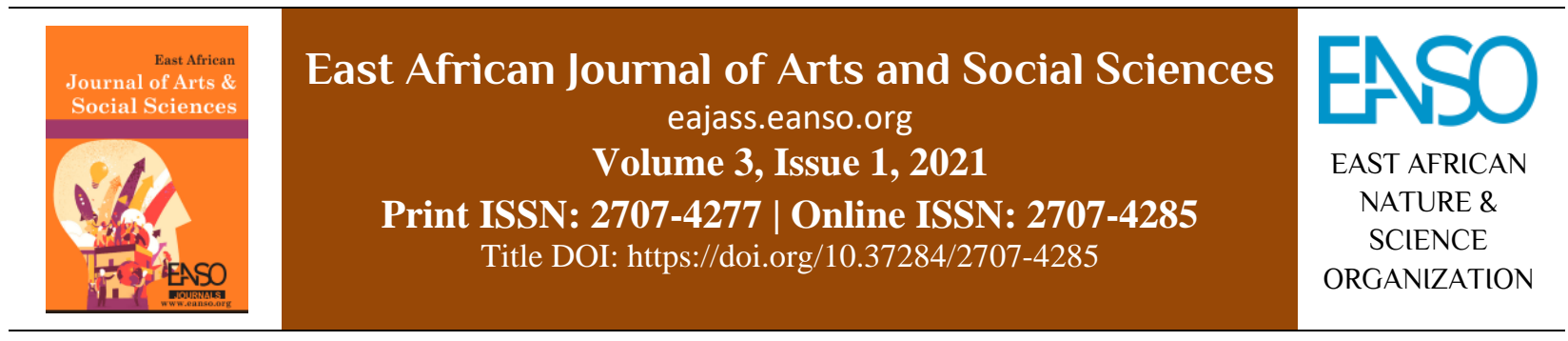

Original Article

\title{
Thematic Approach and Derivation of Subject Matter as an Avenue for Expression and Expressiveness in Painting: Analysis of Selected Paintings by Kenyan Contemporary Artists in Nairobi, Kenya
}

\author{
Dr. Kamau Wango ${ }^{1 *}$ \\ ${ }^{1}$ Department of Fine Art and Design Kenyatta University, P. O. Box 43844 - 00100, Nairobi, Kenya. \\ *Correspondence email: kamauwango@gmail.com.
}

Article DOI: https://doi.org/10.37284/eajass.3.1.356

\section{Article history: ABSTRACT}

08 July 2021 In painting, just like in other disciplines of art, a thematic approach is often applied by artists in their work because themes define all aspects of human endeavour. A thematic

Keywords: approach is also important in the derivation of subject matter that artists ultimately pursue in their work. It can be said that any painting that is executed can be

Painting, compartmentalised to fit within a given thematic pattern. Artists often, but not always, Painting Style,

Theme,

Subject

Matter,

Content,

Context actively consider the essence of the theme itself; at times, they instinctively or spontaneously express something on canvas. It is presumed that the 'intent of the artist', at any given time, is to depict or express some phenomenon that is derived from the intricacies of human endeavour, behavioural traits, experiential sources, or from an individual's own emotions and feelings. Ideally, a subject matter emanates from a particular theme, but it is also generally acknowledged that artists do not always necessarily base their work on a theme as a springboard to their core intent, but that the theme ultimately emerges by implication. A theme is too broad to be compressed into a single pictorial composition and, hence, each theme is interpreted into a retinue of ideas by cohorts of artists. A theme, by its description, is also not explicit because it is a guiding or emanative factor; therefore, it is often implied. It would be unusual, however, that an artist fails to put in perspective his or her thematic foundation in describing the final piece of work because artworks always have some thematic connotation even if it is not deliberately intended by the artist. In this regard, there are some kinds of artworks that bear weighty thematic foundations and others that bear some form of useful thematic content embedded in their meaning. This paper seeks to determine the extent to which the concept of the thematic approach is used by artists to derive subject matter in their painting and whether their subsequent paintings are, therefore, theme-specific or are as a result of creative spontaneity. Further, it seeks to

92 This work is licensed under a Creative Commons Attribution 4.0 International License. 
find out the nature of the subject matter, the artist's motivation and inspiration and whether the resultant paintings are effective in rendering the intended visual message to the audience. A powerful theme is not necessarily a fundamental prerequisite for powerful artwork since artworks are rendered differently by different people, but a powerful artwork is often a good indicator of a potent theme. This paper also examines the stylistic approach, content and context applied by the artists in their paintings. The paintings featured in this paper are those done by some of the contemporary Kenyan artists working independently at different studio locations in Nairobi, Kenya. They were identified and interviewed by fourth-year students at Kenyatta University in their study of the local art scene as part of their wider development of individual painting styles.

\begin{abstract}
APA CITATION
Wango, K. (2021). Thematic Approach and Derivation of Subject Matter as an Avenue for Expression and Expressiveness in Painting: Analysis of Selected Paintings by Kenyan Contemporary Artists in Nairobi, Kenya. East African Journal of Arts and Social Sciences, 3(1), 92-120.- https://doi.org/10.37284/eajass.3.1.356
\end{abstract}

\title{
CHICAGO CITATION
}

Wango Kamau, 2021. "Thematic Approach and Derivation of Subject Matter as an Avenue for Expression and Expressiveness in Painting: Analysis of Selected Paintings by Kenyan Contemporary Artists in Nairobi, Kenya". East African Journal of Arts and Social Sciences 3 (1), 92-120. https://doi.org/10.37284/eajass.3.1. 356

\section{HARVARD CITATION}

Wango, K. (2021) "Thematic Approach and Derivation of Subject Matter as an Avenue for Expression and Expressiveness in Painting: Analysis of Selected Paintings by Kenyan Contemporary Artists in Nairobi, Kenya", East African Journal of Arts and Social Sciences, 3(1), pp. 92-120. doi: 10.37284/eajass.3.1.356.

\section{IEEE CITATION}

K. Wango, "Thematic Approach and Derivation of Subject Matter as an Avenue for Expression and Expressiveness in Painting: Analysis of Selected Paintings by Kenyan Contemporary Artists in Nairobi, Kenya”, EAJASS, vol. 3, no. 1, pp. 92-120, Jul 2021.

\section{MLA CITATION}

Wango, Kamau. "Thematic Approach and Derivation of Subject Matter as an Avenue for Expression and Expressiveness in Painting: Analysis of Selected Paintings by Kenyan Contemporary Artists in Nairobi, Kenya". East African Journal of Arts and Social Sciences, Vol. 3, no.1, Jul 2021, pp. 92-120, doi:10.37284/eajass.3.1.356.

\section{INTRODUCTION}

The essence of themes in this paper is not seen in the context of a thematic exhibition since the artists have neither come together to purposely exhibit their work nor is it about the thematic arrangement of an exhibition that covers work within a given historical period. There is often the tendency to extract themes from finished artwork that is already on display and thereby categorising that work according to the emergent themes and the historical period in which they were done. In other specific instances, such as artistic caucuses or artistic residencies, artists respond to certain identified themes that are perceived to be pertinent or universal and proceed to interpret them in their own individual styles in order to derive varied responses. This paper, however, approaches this matter from the perspective of determining whether or not individual artists bear a deliberate impetus towards the derivation of subject matter that is emanative from desired themes as a reference point towards constructing meaning. The paper seeks to examine how contemporary artists deal with and explore themes as they apply to the unfolding circumstances around them, where such application culminates in the formulation of ideas that embody aspects of the themes. Themes themselves are seen to bear great significance as reservoirs for potent artistic ideas mainly due to the universality of their appeal. But it would not, perhaps, escape a critic's attention that artists tend to respond to and interpret these universal themes in tandem with their local environment in order to achieve contextual value that resonates and, therefore, elicits better and more purposeful responses from the audience. 
There are broad themes that are universal and those that are, in their application, more aligned with the local environment or local peculiarities. There are also themes that are engraved in world history or are deemed particularly pertinent because of their transcending global value as well as their current relevance. These themes have been used and continue to be used to link artworks across time. In this regard, it is unlikely that themes that pertain to the complexities of human nature, societal dynamics, freedom and social change, conflict and adversity, identity, human and the environment, leadership and heroism will expire or cease to engage and fascinate artists and their audiences any time in the future. Livneva (2018) observes that:

Themes such as the human body or natural phenomenon, are 'universal' and of relevance to a wide range of audiences and their experiences. They also provide many layers of information and endless possibilities for interaction and interpretation but they are physical.

The concept of a thematic approach to painting is intertwined with the wider purpose of art. Livneva asserts that "art ideas and themes enable the viewer to understand that certain topics are not wholly obscure and can be as relevant today as they were two hundred years ago." On the essence of art itself, Livneva notes that "the true test of great art is its ability to express the inner realities of life, those realities that don't change according to time and place, that have a universal application." This assertion remains true in the context that these realities, though they do not change in their nature, may play out differently in the various varied environments, or what can be referred to as 'theatres of manifestation', which is what people in those environments understand and internalise.

The world and society have changed drastically within the last three decades and certainly in the era of the internet. The engagement with themes amongst contemporary artists is seen in the context of the rise of new media and the subsequent visual culture as well as the growth and awareness of diversity, individual and collective rights and the need for communicative space. This has meant that the art world has experienced significantly expanded frontiers.

\section{Necessity of Themes in Galvanising Ideas in Painting}

The importance of themes in the generation of subject matter in the art cannot be over-emphasised. It is notable that all human endeavour, occurrences, activities and events can literally be compartmentalised into themes. To put this in perspective, if human life, which encompasses the human experience as it is known today was to be seen as a huge theatre of manifestation, then this manifestation would only unfold in terms of fundamental thematic compartments, be they religious, political, social, economic, cultural, humanistic, philosophical, naturalistic and many more. These would in turn be further subcompartmentalised into thousands of sub-themes that would describe in more detail how human beings live, operate and behave. This 'theatre of manifestation' is, however, not actually hypothetical; it has played out through the ages and artists have played a significant role in the thematic interpretation of their respective historical times. Themes, in this context, are like an infinite reservoir of ideas and a genesis of artistic thought. The engagement of themes in art is a spontaneous process; themes are not selected and availed to the artist to mechanically work upon like artistic fodder, rather they are embedded in the creative resourcefulness of the individual artist; this is why there is always great diversity in the creation and interpretation of artwork even though the artists may be responding to the same theme.

Themes are, therefore, broad guiding factors that direct an artist's ideas towards a certain profoundness and help anchor those ideas as potent social commentaries and opinions. This is much more so because, after all, ideas themselves do not occur in a vacuum without any purpose or motivation. Themes are very useful in the galvanisation of imageries that flow in the mind that are often the formative source of the formulation of artistic compositions that ultimately culminate in the construction of meaning. It is highly unusual for one to view a painting and not somehow unravel the broad theme even if the artist is not present to explain the genesis of the painting. In describing the essence of themes, Berends (2018) perceives a theme as being like a framework upon which an 
artist proceeds to create his or her work and observes that a theme is:

\begin{abstract}
Almost like an umbrella under which you create your paintings, gives an artist a chance to develop his or her work and explore the creative possibilities both technical and visual. I believe that when working without a framework, you run the risk of touching only the surface of a creative process that could lead you to more exciting works of art.
\end{abstract}

There is of course a historical basis upon which the use of themes in art has always been evident. Ancient cave paintings dating back to the Palaeolithic era featured certain hunting themes, depicting large animals. It is theorised that these paintings could have been an account of past hunting epics or could have been part of cave rituals that paved the way for future hunting success. The legacy of Renaissance humanism and its emphasis on classical mythology, for instance, is perhaps the most dramatic. Renaissance artists, who saw themselves as individuals of great intellect, gave great emphasis upon the human experience in their art, and human beings became an important subject of study; and this idea has continued to fascinate artists in modern times. In examining the themes that artists in Kenya pursue today, the idea is to determine what role they reserve for themselves in a modern dispensation and whether these themes matter to them in the way they interact with their audiences and society in general.

\section{Derivation of Subject Matter, Form, Content and Context in Painting}

These terms often appear confusing to students when examining a painting or any other artwork. They are, however, fundamentally related and intertwined and only serve to present and explain the painting holistically. Carrubba (2016) describes subject matter as 'the basic idea contained in a work of art.' In drawing a connection to the content, she adds that "subject matter is a fairly simple idea contained within the work of art. It becomes more complex when we add in the content." Ocvirk et al. (2013) identify the three components of art as subject, form and content and proceed to give an insight into the interrelation between the three components as follows:
Subject, form, and content have always been the three basic components of a work of art, and they are wed in a way that is inseparable. In general, subject may be thought of as the "what" (the topic, focus, or image); form, as the "how" (the development of the work, composition, or the substantiation); and content, as the "why" (the artist's intention, communication, or meaning behind the work).

The subject matter in art is therefore, what the artist wishes to portray either derived purely from a thematic basis or the crystallisation of an idea or from one's inner feelings or emotions. The artist then uses objects or figures to render this subject matter in a way that can be identifiable as a pictorial composition either through representational images, that is, those that have a close resemblance to their real-life referents. The artist can also choose to use varying degrees of abstraction in a continuum from those that have some modicum of representational value to the completely broken-down nonrepresentational pieces.

Form refers to the holistic and deliberate organisation of the artwork using formal elements. Once the initial subject matter has been identified, the artist then embarks on the formal arrangement of the work utilising the elements of art as building blocks and using the principles as guides. This organisational interaction between elements and principle culminates in a well thought out composition that encompasses the artist's holistic idea and suggests the intended meaning. Ocvirk et al. (2013) note:

Based on the intended expression, each artist can arrange the elements in any manner that builds the desired character into the piece. However, the elements are given order and meaningful structure when arranged according to the principles of organisation, which help integrate and organise the elements.

Content refers to the notion of the construction of meaning that is derivable from the completed artwork. This means that once all the formal arrangement has been finalised and the initial idea has been organised into form in terms of what the artist intended, then the remaining fundamental question gravitates around what the painting itself means and what its essence amounts to. This ushers 
in a new level of engagement with the painting which is the 'interpretive' stage. This is not easy because the emotional, intellectual or commentary content all imply that there is an underlying or engrained message emanating from the artist which is now subject to interpretation by the viewer. This, in turn, often leads to multiple interpretations. Ocvirk et al. (2013) further observe that:

Of the three components of art, content may be the most difficult to identify because the audience, without direct communication with the artist, must decipher the artist's thoughts by observing the work's subject and form.

In addition, Carrubba (2016) in defining content as interlinking with subject matter observes that "the basic definition here is that content is the themes and messages contained within a work of art, and conveyed through the subject matter, as well as symbolic and iconographic references."

Context refers to the meaning derived from artwork in view of its environment and historical placement, particularly the events and circumstances that led to its inspiration and motivation that galvanised the artist's intent. Carrubba (2016) writes that "Context can be defined as the meaning of a work of art, impacted by its history, the mode of encounter and surroundings, and the writings about that work of art." In any artistic endeavour, there is no art that harbours meaning that has no contextual basis. This is because no creative work is based on a 'non-ideal or a 'non-theme' or non-existent emotive undercurrents, all of which are, in retrospect, founded upon a given contextual anchorage. Context is, therefore, a fundamental factor in unravelling meaning in works of art. If a painting, for instance, is not interpreted in its context, particularly its social/cultural or historical context, there is a significant probability that its meaning will be misconstrued or even misunderstood altogether. In a simple and precise description of the context in a work of art, Belton (1996) observes that "context means the varied circumstances in which a work of art is (or was) produced and/or interpreted." $\mathrm{He}$ proceeds to give three interesting levels of complexity as primary context as that pertaining to the artist; secondary context, as that pertaining to the social environment in which the work was produced and tertiary context as that pertaining to the field of the work's reception and interpretation. He concludes that "Content is "what" the work is about, form is "how" the work is, and context is "in what circumstances" the work is (and was)."

\section{ANAL YTICAL FRAMEWORK}

The work in this paper was analysed using the following framework which consists of basic tenets for analysing any artwork.

\section{Formal Analysis}

The use of formal analysis has routinely been used to examine artwork in order to understand how a particular artwork has been formulated and to decipher meaning according to what the artist may have intended to achieve through the work. Formal analysis is useful because every artwork bears a basis upon which it is constructed; how the artist works within the picture plane, what he or she places and interweaves and how the entire pictorial composition is envisioned. It, subsequently, involves the use of elements (what the artist uses) on one hand and principles (how the artist arranges the elements) on the other. Glatstein (2009) observes that:

Formal analysis is an important technique for organising visual information. In other words, it is a strategy used to translate what you see into written words. This strategy can be applied to any work of art, from any period in history, whether a photograph, sculpture, painting or cultural artefact.

In examining an artwork and in the quest to appreciate it, a viewer may wish to observe pertinent aspects of the artwork, be they colours, textures, shapes, masses/spaces and tones. Other pertinent parts of the artwork could be compositional such as balance, proportions and focus. Therefore, an artist is required to take time to undertake this formal arrangement in a way that makes his or her work appealing to the viewer in terms of compositional acumen. Ocvirk et al. (2013) observe that:

As a component of art, the word form refers to the total overall arrangement or organisation of an artwork. It results from using the elements of art, giving them order and meaning through the 
principles of organisation. When studying a work's form, we are analysing how the piece was created. More specifically, we are examining why the artist made certain choices and how those choices interact to form the artwork's final appearance.

It is not always necessary to break down the work into formal details in order to appreciate it and not all viewers are equipped with that kind of training. However, when a piece of art is completed, there is a way in which the viewer's eyes are able to flow over the work, culminating in a holistic visual appreciation that is often deemed adequate for comprehending the work. Glatstein (2009) further notes that:

A good place to start formal analysis is to look at a work of art and take note of how your eye moves around the object. Where does your eye go first, and why were you attracted to that part of the image? What colours, textures, and shapes appear in the image? What did the artist include in the composition to guide your eye or to direct your gaze to a certain part of the image?

\section{Principles for Interpreting Art}

Apart from the formal analysis approach to the work itself, an artwork and paintings in particular, may be examined from a different approach that provides an avenue for discussion. This approach involves other factors that are important for comprehending artwork which all pertain to 'interpretation'. It is presumed, for instance, that any artwork bears some kind of meaning, covert or overt, that it is 'about' something. It is further presumed that in embarking on an artwork, the artist often intends to express something and, hence, wants the audience to comprehend, empathise, internalise or enjoy this intent or whatever emotion the work may, subsequently, evoke. The quest to fathom the essence of the work, therefore, precipitates an 'interpretive dialogue' based on certain guiding principles. Although these guiding principles may suggest a more or less intellectual approach to interpretation, this study posits, however, that the quest for interpretation is a positive undertaking because artworks by their nature 'need' to be interpreted in order for meaning to be derived. The outcome of interpretation makes the artworks not only visually attractive but expressively potent. Barrett (1994) outlines some of these guidelines as follows:

- Responsible interpretation presents the work at its best rather than its weakest light.

- Interpretations are arguments.

- Interpretations are persuasive.

- Good interpretations of art tell more about the work than they tell about the interpreter.

- Good interpretations have coherence, correspondence and inclusiveness.

- An interpretation of an artwork need not match the artist's intent for the artwork.

- The objects of interpretations are artworks, not artists.

- Feelings are guides to interpretations.

- Interpretations are not so much about right but more or less reasonable, convincing, enlighting and informative

Barret examines each of these guidelines in detail, but it is apparent that even at face value, each plays a significant role in the way any artwork is interpreted. It is, for instance, in the spirit of artistic goodwill and fair play that artwork is viewed with a sense of interpretive positivity in order for it to meet its highest potential. When arguments are made about an artwork, they are positive, forward-looking and persuasive, aimed at consolidating meaning. The extent to which these arguments are deemed successful underscores the overall visual value of that work. When an interpretation of an artwork does not necessarily match the artist's intent, that implies the onset of multiple interpretations and the notion of perceived alternative opinions, which are heathy for artistic discourse. When interpretations are not so fixated on a single direction of meaning, then they open space for much more opportunities for expanded reasoning, enlightenment and informativeness. 


\section{Contextual Analysis}

Interwoven with the whole realm of interpretation, the viewer of any given artwork, in this case, paintings, cannot ignore the omnipresent 'contextual curiosity or the driving urge to comprehend certain profound paintings in the context in which they were created. Contextual considerations and influences are always tethered to the artist's intent, but they stretch beyond these intents. Every painting is better understood if its context is known, particularly the social/cultural environment in which the artist operates and in which the painting is done. This is particularly so both in 'expression' where the artists create paintings that involve feelings and emotions and in 'expressiveness', where the artist's appeals to the emotional responses of the audience. Though it is not easy to delve into context all the time since the artist is seldom available to explain this context, visual hints are almost always present, particularly use of symbolism and iconography, visual melodrama and other strategies of execution of work including facial expressions.

As indicated earlier, contextual analysis usually occurs alongside formal analysis but concerns itself more with certain aspects of the cultural content that affects the artist and his or her audience. These aspects are religion, politics, economics, social organisation and artistic influences. When one, therefore, examines a finished painting, one way in which to effectively derive meaning is to bear in mind its contextual placement. This necessitates a closer look at how the artist incorporates these aspects and puts them in perspective in the construction of fundamental idea(s) in the painting. In describing the primary context that concerns the artist, Belton (1996) observes that:

Primary context is thus that pertains to the artist: attitudes, beliefs, interests, and values; education and training; and biography (including psychology), special mention must be made of the artist's intention and purposes because it is very easy to fall into a trap called the intentional fallacy.

He further identifies the secondary context as "that which addresses the milieu in which the work was produced: the apparent function of the work at hand; religious and philosophical convictions; social political and economic structures; and even climate and geography, where relevant." He identifies the tertiary context as "the field of the work's reception and interpretation."

'Context' is, therefore, an important factor in examining artwork. In explaining the approach to contextual analysis, Barenscott (2016) observes that:

Context must be assessed from a large number of perspectives in order to create a more dynamic assessment. It is not enough, for example, to research only the artist's intention for the work-even if they wrote or stated exactly what the work was meant to be about - since that fact alone does not account for the multiple and sometimes conflicting meanings that can circulate around a visual object. 
ANALYSIS OF WORK

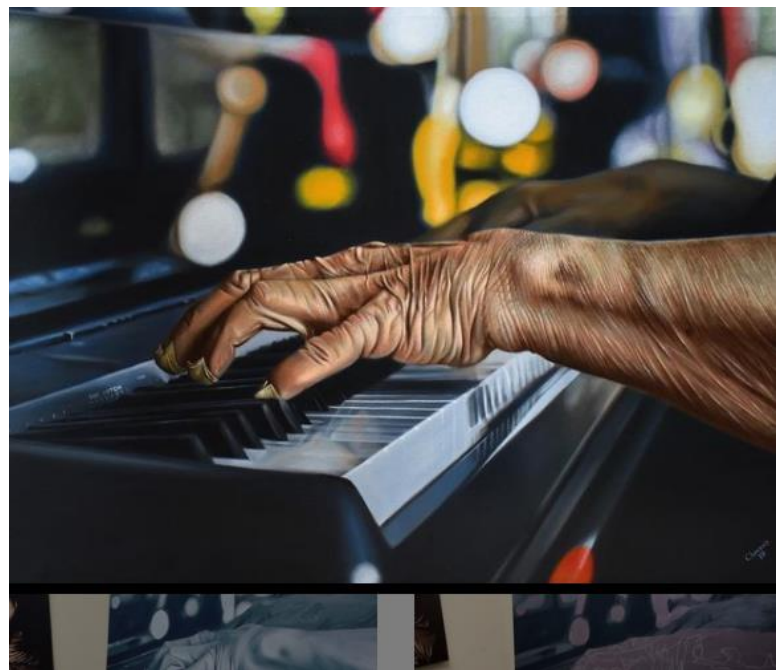

Plate 1. 'Hands on Piano' (2019)

Artist: Clavers Odhiambo

Oils on canvas: $140 \times 100 \mathrm{~cm}$

Source: Instagram @ claversodhiambo

'Hands on Piano' (Plate 1) is a hyperrealistic piece showing the study of the arm, hand and fingers as they work the piano keys. It focuses on the folds on the arm and fingers as the fingers stretch into position to make the music. Hyperrealism is a style that seeks to supersede photographic effects and refines these effects into a new form of flowless, superfine art that shows details better than its referent photograph. The fine textural effects on the arm suggest that the astute musician is an elderly individual. Started in the mid-1970s and relying on digital imagery and the high-resolution pictures produced by digital cameras, hyperrealists aimed at taking their art a notch higher than photorealists to create a work so fine with details that are not fathomable in reality, therefore, creating an illusion of new reality. It is unlikely that even a photograph would perhaps present details of folds as they are presented in this painting. Since the details of the folds are so fine and intriguing, they create a new reality through which we may wish to see the hand actually look-like. The rest of the painting is also very finely done with a photographic variation of tones and suggestion of blurred background colours.

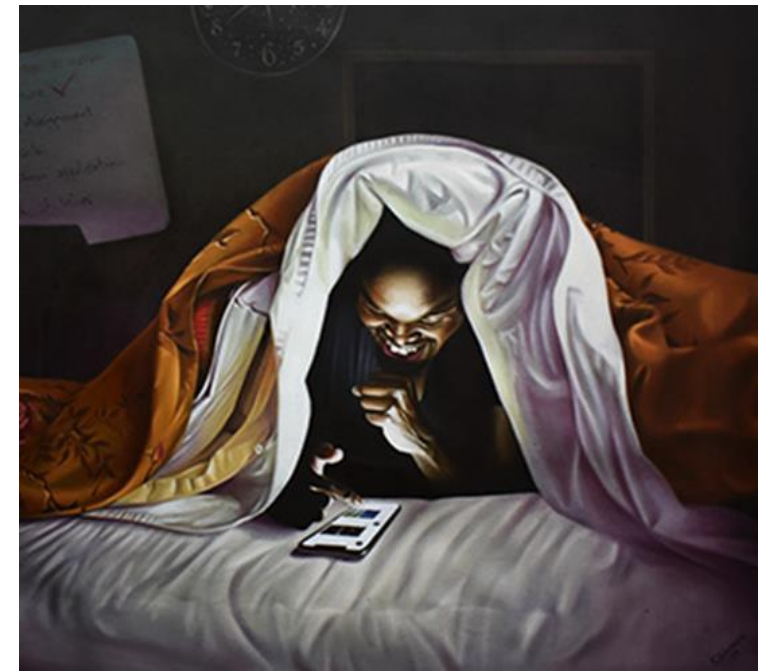

Plate 2. 'First things first (2019)

Artist: Clavers Odhiambo

Oils on canvas: 120 x $100 \mathrm{~cm}$

Source:Instagram @claversodhiambo

The artist uses illuminative effects that help, for instance, to specifically focus light on the hand, giving it its prominence.

'First things first (Plate 2) is a self-portrait that depicts an obsession with the cell phone. The artist uses the 'chiaroscuro' effect to illuminate the most pertinent parts of the painting, in this case, the face, hands and the cell phone. The bright light from the phone reflects upon the white part of the duvet, surrounded by a very dark background. "One of the most important ways in which artists can use light to achieve particular effects is in making strong contrasts between light and dark. This contrast is often described as chiaroscuro (Gale, 2018, citing Treherne, M). The propped-up figure in the painting depicts the urgent need to scroll through the phone, as suggested in the title. It implies the obsessive, almost addictive reliance on the phone, the internet and social media as the sole source of all types of information. The painting itself is well executed with hyperrealistic folds on the duvet's drapery. 


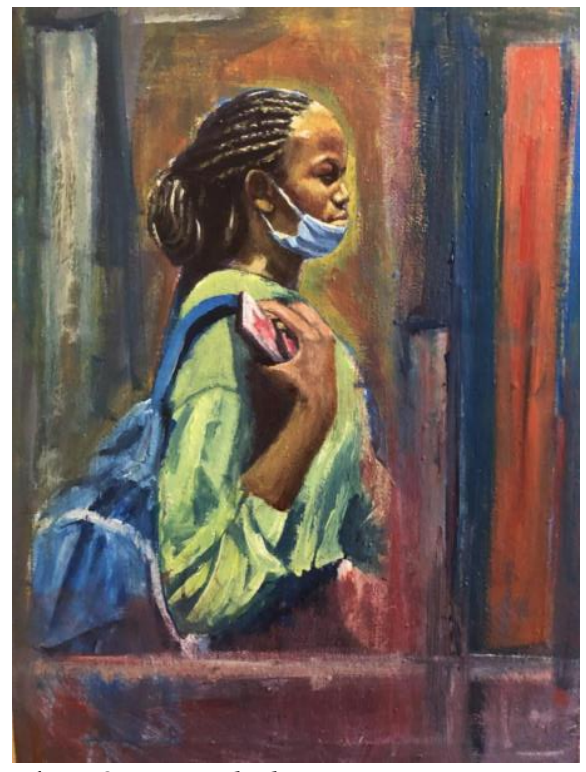

Plate 3. 'Untitled' (2020)

Artist: Robert Ratemo

Acrylics on canvas: $62 \times 37 \mathrm{~cm}$

Source: Instagram @4ratemorobert

Plate 3 depicts the era of COVID-19 and how it has impacted the youth, how the youth comprehend the virus and how it interferes with their daily lives and routine. The artist uses the wearing of the mask as symbolic of this unprecedented situation. The girl in the painting wears her mask below her mouth, which is consistent with the misunderstanding of how the virus spreads or could be a show of defiance or mask fatigue. She is also depicted carrying her cellphone. The painting is pleasantly executed, with the girl's facial structure smoothly painted and well illuminated with the effect of natural light purposely focused upon it. The texture of the hair is also well depicted. This light effect also falls upon her green top and parts of the blue backpack; the rest of the background is done with the application of bold brushstrokes. Whenever artists use the chiaroscuro effect, they create areas of dark contrasting shadows, the idea of which is to focus attention upon the centre of interest.

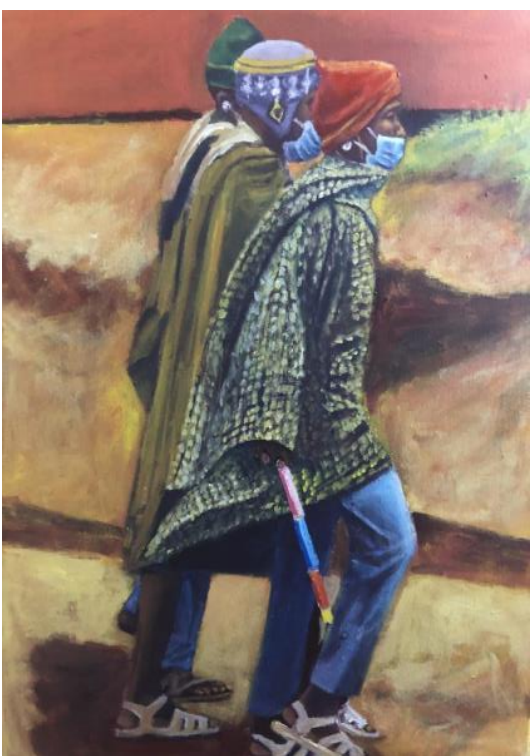

Plate 4. 'Untitled' (2020)

Artist: Robert Ratemo

Acrylics on canvas: $62 \times 37 \mathrm{~cm}$

Source: Instagram@4ratemorobert

Plate 4 is a painting of walking villagers who appear like nomadic herdsmen, wearing COVID-19 masks. This underscores the importance of COVID-19 prevention measures, particularly the wearing of masks. This is testimony that this message has permeated all corners of the country and that the pandemic affects all communities. Apart from the masks, the artist studies other cultural aspects of the three walking images, such as their attire, including patterns and folds. The use of the effect of natural light against shadows helps to create contrasts which in turn illuminate parts of the painting, indicating the direction from which the natural light is coming. The artist de-emphasises the background, ensuring that the three walking men remain the centre of interest in the painting. Other than the depiction of the cultural element and the wearing of masks, the painting does not seem to carry any other pertinent message. 


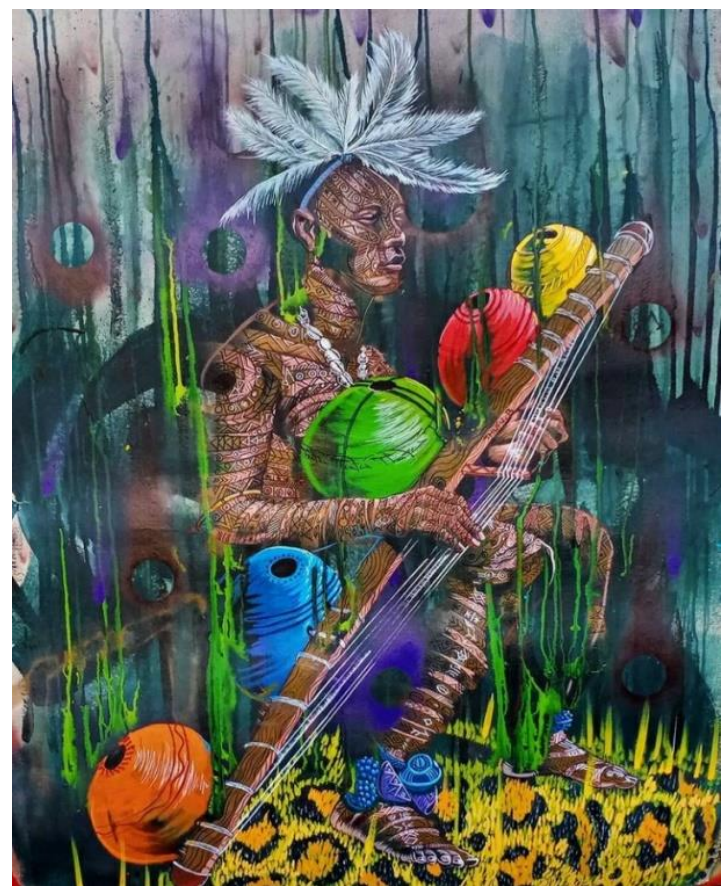

Plate 5. 'Thu'm'

Artist: 'Thufu B'

Mixed media on paper: $140 \times 112 \mathrm{~cm}$

Source: Instagram @Thufu_b

Thu'm (Plate 5) is a celebratory painting depicting the pomp and colour of African traditional music under the broad theme of culture. It shows a sitted traditional musician with intricate body decorations, playing his traditional string instrument and dressed in full traditional regalia, including a feather headdress, probably composed of white ostrich feathers. The artist uses pleasant bright colours to create a sense of warmth and rhythm including the leopard skin mart on the floor. He also uses light vertical purple/blue brushstrokes to complete the background that helps to highlight the musician as the centre of interest.

Dot.com (Plate 6) depicts the generation that became associated with the dot.com era from the year 2000. This generation was characterised by a new kind of boldness, identity and defiance. The

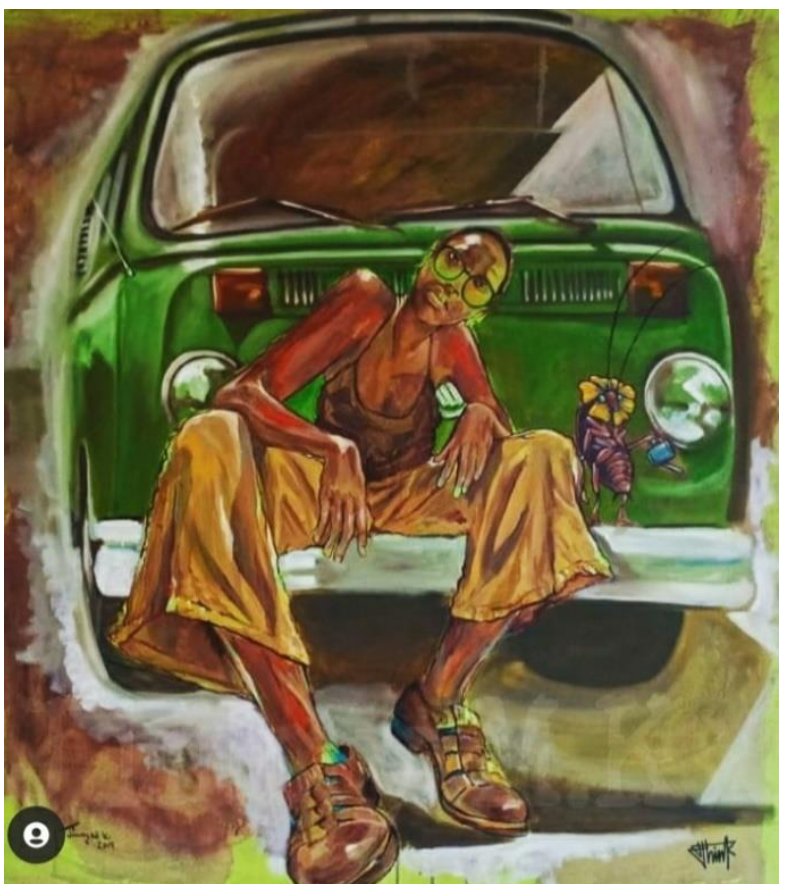

Plate 6. 'Dot.com' (2019)

Artist: Jimmy Kitheka

Oils on canvas: $120 \mathrm{~cm} \mathrm{x130} \mathrm{cm}$

Source:Instagram @Jimmy_kitheka

youth described themselves as a 'neo-generation' bubbling with ideas and a new way of doing things. The dot.com era brought about a lot of new technological advancements, particularly in the sphere of global communication and connectivity with the onset of the internet. The digital era embraced a new way of communicating, processing and disseminating information as well as doing business. It also ushered in a new way of thinking such that new impactful ideas that sounded sophisticated and modern were classified as dot.com ideas, and those that sounded outdated were dismissed as analogue, symbolising old school. The painting depicts a young woman in a defiant pose wearing large sunglasses, oversized shoes, loose string blouse and wide-bottomed pants, sitting in front of an old van. All these are symbolic of a new generational identity. 


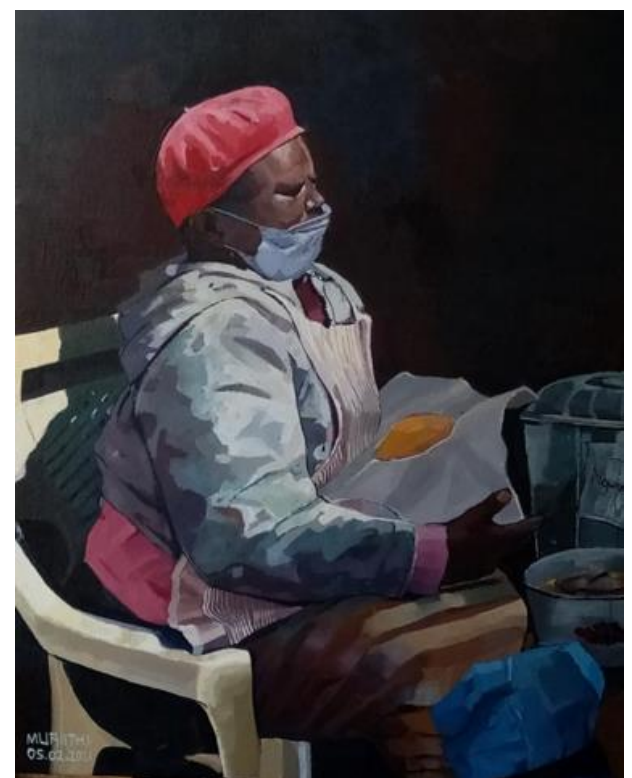

Plate 7. 'Mama Ngwaci' (seller of sweet potatoes) Artist: Samuel Mureithi

Acrylics on canvas: $100 \mathrm{~cm} \mathrm{x} 80 \mathrm{~cm}$

Source: Instagram @mureithi contemporary

In 'Mama Ngwaci' (Plate 7), the artists depict a seller of sweet potatoes. Just like the fruit sellers (Plates $13 \& 14$ ) the artists pays homage to this resilient woman who sells cooked sweet potatoes to her customers the whole week long, never failing and never absent, despite the challenging nature of her small business. Though people tend to dismiss such humble small businesses as insignificant, these women make a living out of them and manage not only to survive but to find a way of thriving and contributing to the family income. The artist uses chiaroscuro to shine light upon the woman's image, which is well-executed against a very dark, empty background helping to focus the eye's attention on the woman as the centre of interest. The artist also uses a combination of colour tones to paint the folds

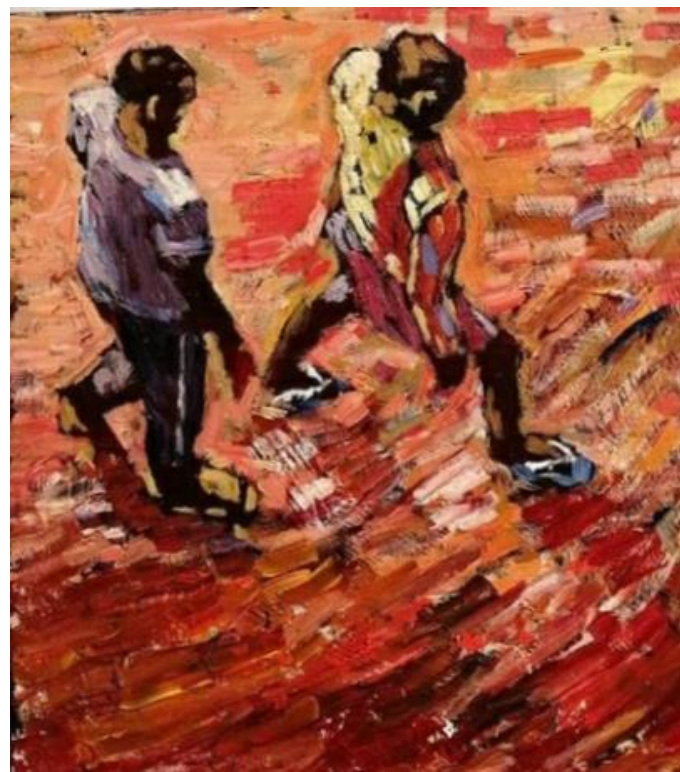

Plate 8. 'Conversations and movements' (2020)

Artist: Michael Nyerere

Acrylics on canvas:

Source:Instagram @Michael_creations

on the woman's jacket as well as the rest of her attire.

The expressionistic 'Conversations and movement' (Plate 8) depicts movement through its bright colours and bold brushstrokes. The brushstrokes themselves suggest the direction of movement. Studied from an aerial view, the artist uses the effect of focused light and shadows to create an illuminating effect upon the two human forms and inserts only the necessary details. Though conversations cannot be rendered visually, they are felt or implied through the visual nature of the gestural poses that suggest movement; people often break into the conversation as they walk together and go about their chores. 


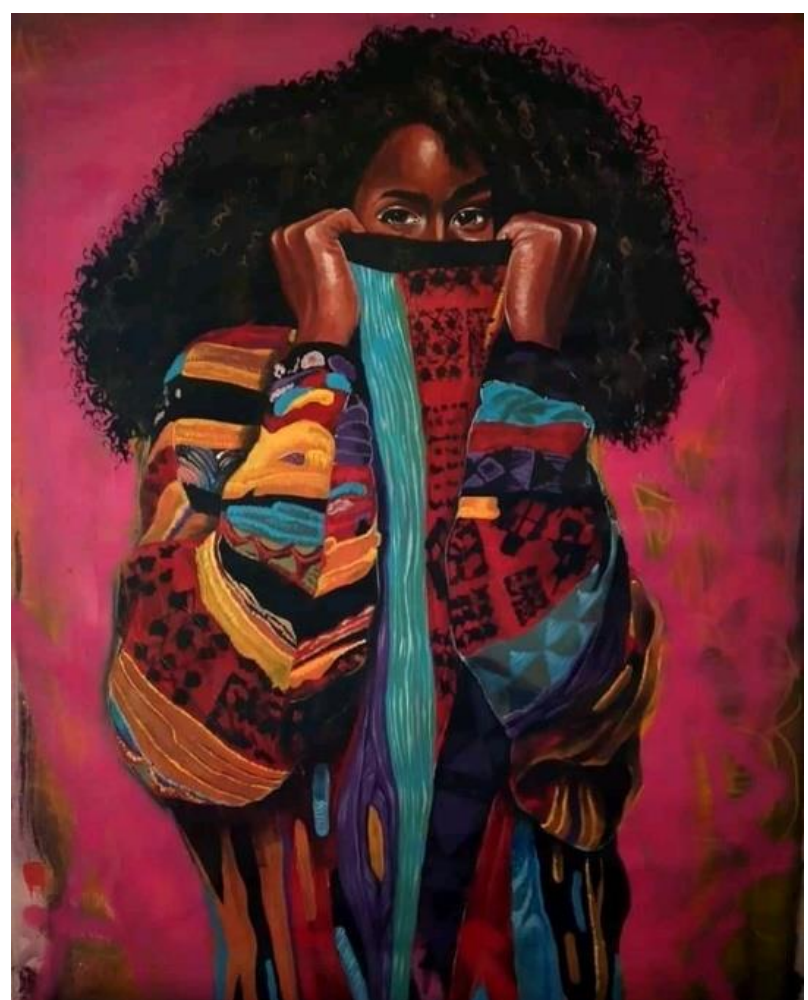

Plate 9. 'Stolen Sweater' 2021

Artist: Eric Mureithi

Acrylics/poison markers on canvas: $90 \times 70 \mathrm{~cm}$

Source: Facebook - Erick stickky muriithi

'Stolen sweater' (Plate 9) is an actual story of a beloved beautiful multi-coloured sweater that went missing from a wardrobe. The distraught artist narrates this episode in a painting that shows the probable culprit adorning the multi-coloured sweater. The girl, perceived as young and innocent, covers her face leaving only her eyes, which is symbolic of guilt; she must not expose her face lest she is identified as the thief. The artist studies the colours of the sweater in almost nostalgic detail as if coming to terms with its loss. The thief, however, remains unidentified; it could be a relative, friend, colleague or just an acquaintance. The painting, by extension, underscores the 'enigma of friendship'; that those close to somebody (symbolised by the notion of access to the wardrobe) would be the same ones who steal something uniquely valuable and personal, in complete disregard of the tenets of friendship. This implies, though, that the notion of friendship is not always based on sincerity. The gist of the message is that those who bear the capability to harm you are those within your closest orbit.

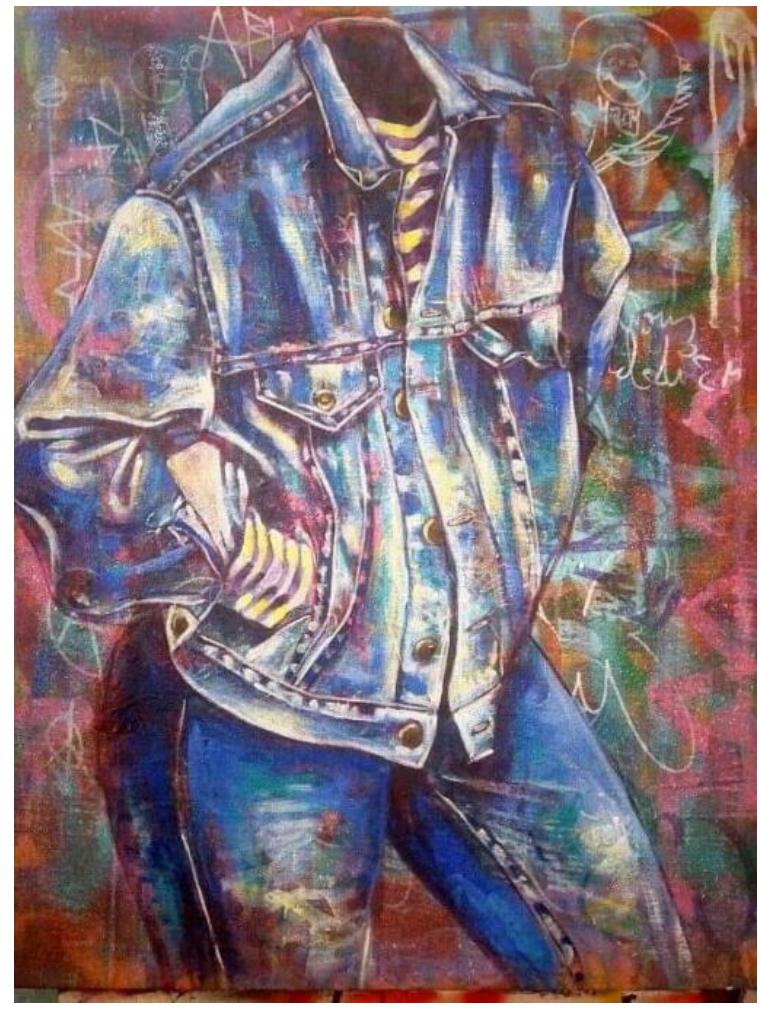

Plate 10. 'Blue on Blue' 2019

Artist: Eric Mureithi

Spraypaint and acrylics on canvas: $90 \times 70 \mathrm{~cm}$ Source: Facebook - Erick stickky muriithi

In 'Blue on Blue' (Plate 10), the artist intended to study the beauty of jeans as a garment; their blue colour, texture and their age-old representation of trendy fashion. But in demonstrating the multiinterpretational nature of paintings, a viewer instead saw the depiction of a surrealistic human image without both body and soul. This surrealistic pseudo-being, represented by the blue jeans with a gestural pose of a human form, suggests then that clothes by themselves are akin to an empty shell if they do not adorn a physical body. In addition, a physical body is in itself of no value if it harbours no soul because then, it bears no living value. The gist of the argument here is that there is always a possibility that individual human beings are not what they appear to be despite what they are adorned with; they may turn out to be quite hollow on the inside in terms of the substance of character, like a body that harbours no soul. 


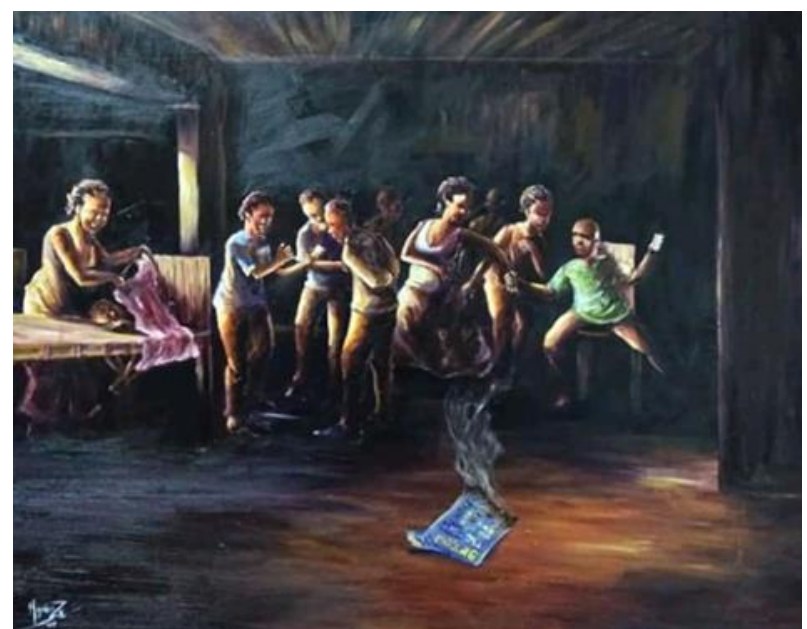

Plate 11. 'Betting Imechomeka' (2020)

Artist: Hannington Gwanzu

Acrylics son canvas: $70 \mathrm{~cm}$ x $100 \mathrm{~cm}$

Source: Facebook - Hannimgton Gwanzu

In 'Betting Imechomeka (Betting has burned down, Plate 11), the artist depicts a visual narrative about the pitfalls of betting and how people get absorbed almost to the point of addiction. There was a time that betting in Kenya had become a social problem that was affecting social and family norms. In the quest to win money, people would bet everything they had, including their entire salaries and school fees. Since betting is based on the concept of anticipative chance, they would, in the circumstances, often lose everything. This would then set-in motion aggravated family upheavals whose main fallout victims would be the women and children. The artist decries this tendency. In the painting, the artist depicts a group of people in a straight-line narrative, engrossed in betting; from an individual reading his results on his cell phone, seated next to hawkeyed women waiting to rip the benefits; to three excited men discussing their odds. The woman on the left covers her child while she

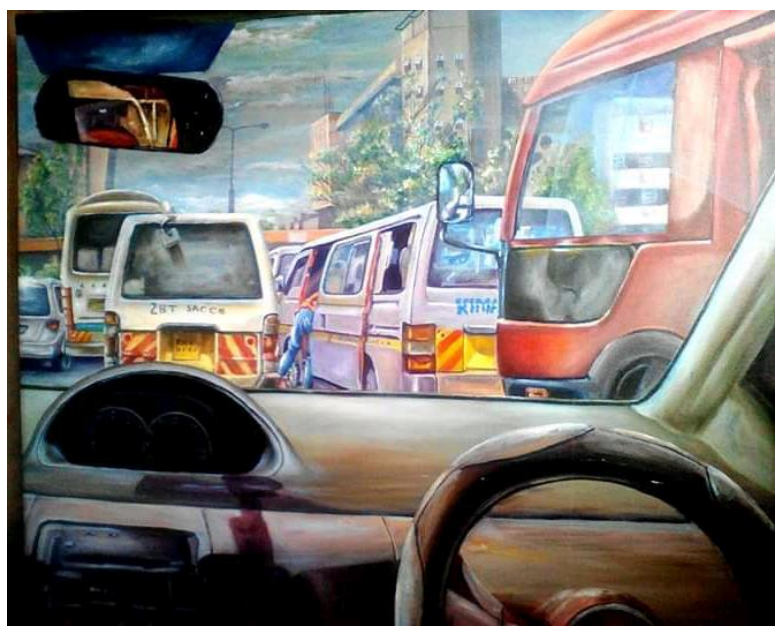

Plate 12. 'Traffic' (2019)

Artist: Hannington Gwanzu

Acrylics on canvas: $60 \mathrm{~cm} \mathrm{x} 60 \mathrm{~cm}$

Source: Facebook - Hannimgton Gwanzu

waits in vain for her betting husband to bring home some food. Influenced by Caravaggio's chiaroscuro, the artist deliberately applies an illuminative effect on the human forms with the light coming from the left of the painting against a dark background. This helps to direct the viewers' attention towards the frenzied action and ensures no distraction. In the foreground of the painting is a burning betting advert printout sheet.

In 'Traffic' (Plate 12), the artist depicts the state of traffic on the streets of Nairobi from inside a vehicle that is also stuck in a traffic jam. Traffic jams are a usual occurrence in the streets of Nairobi, particularly when the notorious public transport vans, locally known as 'Matatus', depicted with a yellow stripe, are involved. The gridlock can, at times, be so debilitating that motorists often spend hours on end in multiple snarl-ups, wasting enormous amounts of valuable working hours. 


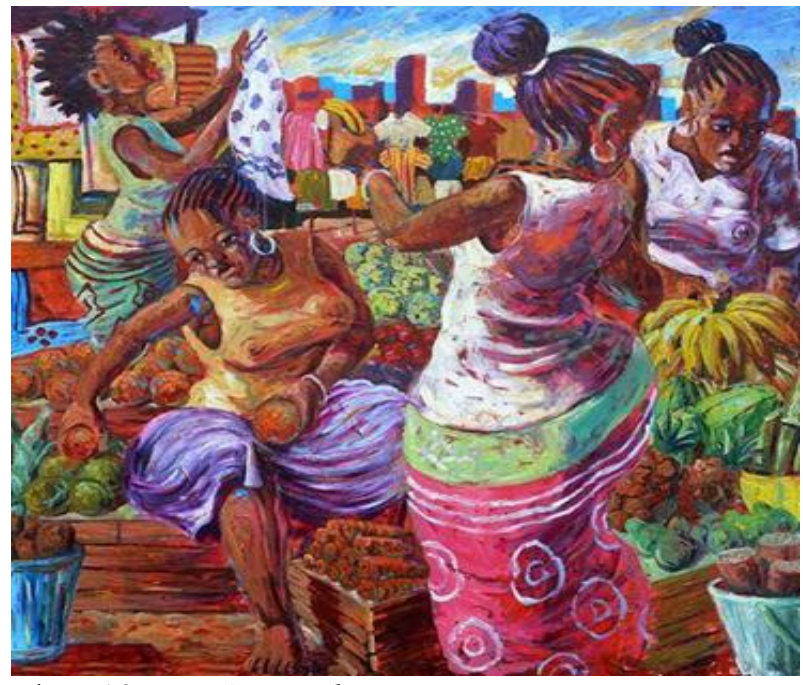

Plate 13. 'At the market' (2010)

Artist: Patrick Mukabi

Acrylics on canvas:

Source: Instagram @artistpatrickmukabi

In 'At the market' (Plate 13) and 'Mama Soko' (Plate 14), the artists depict typical scenes at the fruit market on a bright sunny day. It shows the boisterous African women going about their day's business. The artist depicts the women with their full rounded bodies, pronounced buttocks and full breasts, a description perhaps of the physical features that underscore their femininity. He also features their famous bright coloured and patterned waist wrappers known locally as 'Kangas'. In the background, he features their small businesses fully stocked with an assortment of seasonal fruits, which are a pointer to their acumen and dedication. The artist includes many gestural poses which underscore the spontaneity with which the women conduct their work as well as their mannerisms, but he ensures that the women always take centre stage in each painting. The paintings are themselves not detailed but are well executed with just enough visual information necessary to fit his purpose. But it is, perhaps, the artist's ability to create the feeling or aura of the unfolding scene that is fascinating. These African women are dedicated to their work. They wake up very early each morning to purchase their supplies from the wholesale market in order to make them available to their retail customers every day of the week; that is how they eke out their living which means they play an integral part in generating

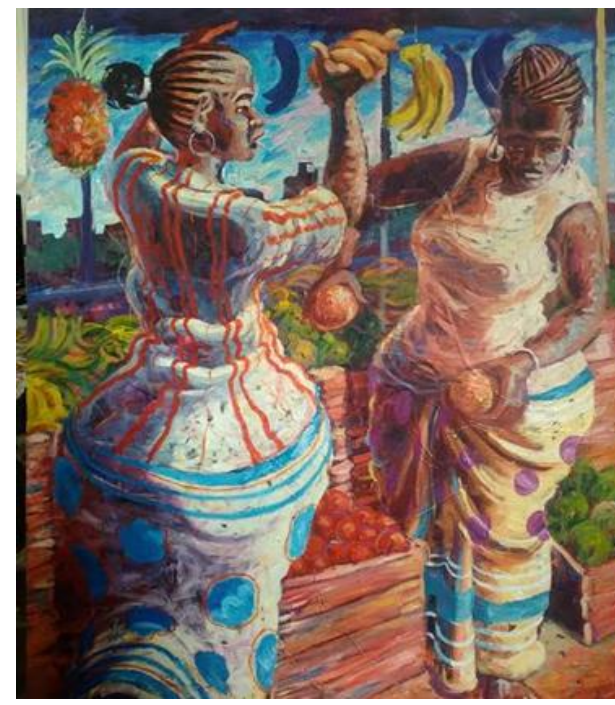

Plate 14. 'Mama Soko' (2014)

Artist: Patrick Mukabi

Acrylics on canvas: $80 \times 120 \mathrm{~cm}$

Source:Instagram @ artistpatrickmukabi

family income. But again, these women are also inclined towards a unique tendency that characterises market women; they talk incessantly, they dance, they multi-task, and their stalls are a hub of activities. They sell when customers show up and when they have a moment to spare, they gossip about any topic on earth that strikes their imagination.

The artist neither attempts to necessarily turn the women into symbols of beauty nor does he seek to objectify them; but seeks to portray them as they are in their natural element. His paintings are a celebration of these iconic market women; hardworking, talkative, joyful, restless, respectful and decent. He says of their resilience, "Women are the fabric of African society. If a woman is poor, the next generation is also poor: how well women are doing is a barometer of the health of the society.' In his obvious fascination with the feminine physical form in portraying the African woman, the artist says that he seeks to portray her unique beauty and form, the kind that he feels no other woman in the world possesses. He, however, has high regard for the women and says, "My approach to the female figure is appreciative; I have a fascination with it. My approach is to also explore the human figure generally." 


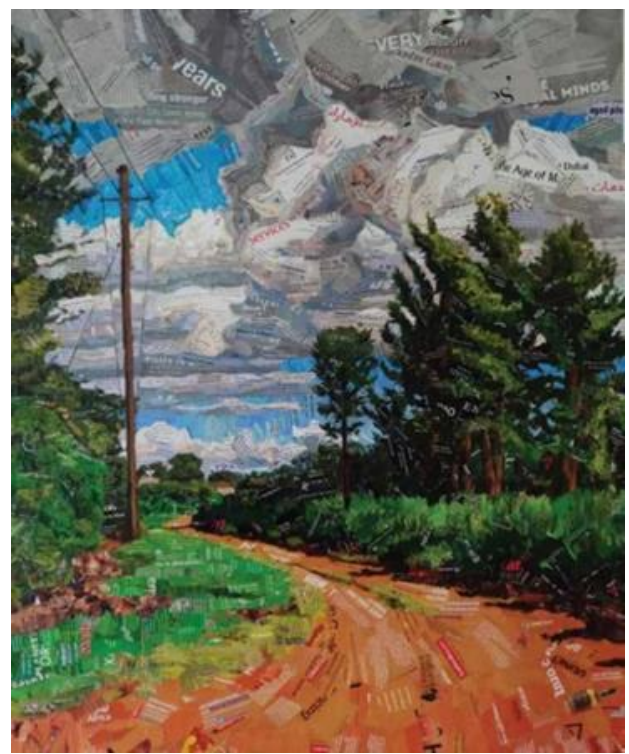

Plate 15. 'Outdoor scenery'

Artist: John Kariuki

Acrylics on canvas:

Source: Instagram @ kariuki_collage

'Outdoor scenery' (Plate 15) is a lively study of a rural African setting. The artist, who says he is inspired by the style of Vincent Van Gogh, uses bold brushstrokes and finely executed perspective to capture the winding dirt road, the vegetation and trees that make the composition. He also uses a combination of white, blues and greys to show the background that shows a distant clear blue sky in the midst of gathering storm clouds. The artist also illuminates parts of the painting with natural midday light suggested by shadows falling directly beneath the vegetation. The painting captures the pertinent details of the scenery with bold yet precise brushstrokes that make the painting life-like, pleasant and enjoyable.

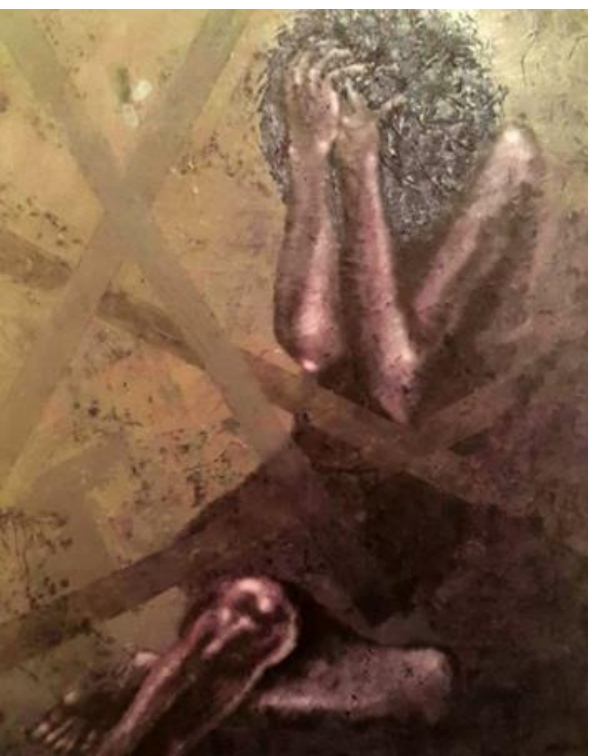

Plate 16. 'Crossroads III' (2017)

Artist: Naitiemu Nyanjom

Mixed media on canvas: $80 \times 100 \mathrm{~cm}$

Source: Instagram @naitiemu

'Crossroads III' (Plate 16) was inspired by the need "to express the deep emotions one goes through while trying to find themselves. Feelings like loss, confusion, hope and emptiness." (Artist) The artist uses a pertinent gestural pose to depict the notion of personal turmoil and despair. These kinds of poses that express extreme emotional stress are characterised by grasping, rending or pulling of hair, hiding of face in the hands, and crouching body positions. Artistically, they are often rendered by focused lighting or illuminative effects on the subject accompanied by dark, eerie backgrounds. The artist used a monochromatic effect to create a dull atmosphere and folded limps to create a cringed position that is expressive of personal agony and embarrassment. 


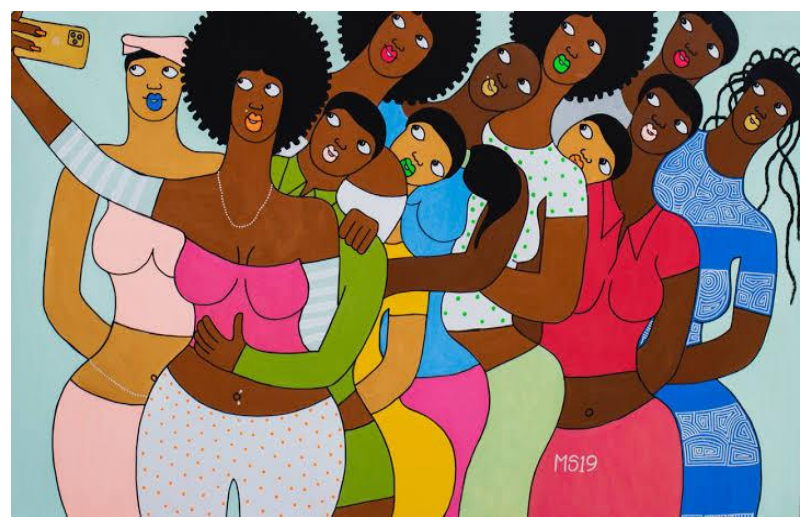

Plate 17. ' 11 Pro max' (2019)

Artist: Michael Soi

Acrylics on canvas: 120 x $100 \mathrm{~cm}$

Source: Circle art Gallery

In Plates 17 and 18, the artist explores the subject matter gravitating around commercial sex work. This controversial subject has traditionally attracted heated debate between two broad categories in society; those who support the moralism stance which condemns and frowns upon commercial sex work, and those who subscribe to the concept of liberal pragmatism, which embraces the practicality of its existence as a livelihood. The moralists contend that this engagement undermines the moralist concept, which they believe should otherwise be the major tenet that regulates holistic human behaviour and moral conduct. The pragmatists not only tolerate commercial sex work but call for its legalisation, regulation and destigmatisation, arguing that women have the right to earn a living. The debate rages on whether commercial sex work or prostitution in its entirety is a social/economic activity or a reflection of society's moral/cultural decadence. The controversy over time, which the artist highlights, has been hinged upon the glaring hypocrisy that has always engulfed commercial sex work, making it one of the most loathed yet also one of the most sought after, underscoring the irony of its existence.

In the paintings, the artist depicts the women in their element in Nairobi's nightlife. In '11 Pro max'

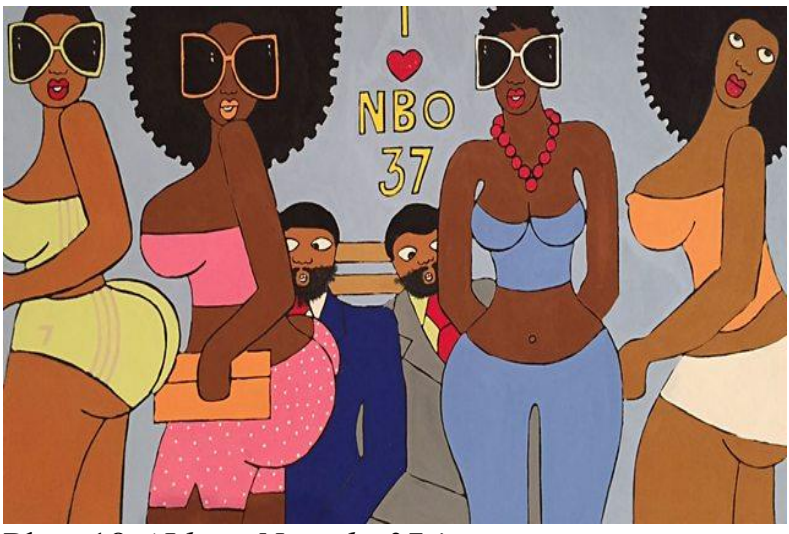

Plate 18. 'I love Nairobi 37.'

Artist: Michael Soi

Acrylic on canvas:

Source: Circle art Gallery

(Plate 17), the eleven women are captured taking a group selfie, suggesting that they are completely at ease and in solidarity with each other and are proud of their socialite work. In 'I love Nairobi 37' (Plate 18), the socialites parade themselves in 'the battle of the socialites', scantily dressed and filing past some well-dressed mesmerised men, suggesting that they have regular, well-to-do 'clients'. In the paintings, the women are presented as thoroughly objectified forms, perhaps of ill-repute, perhaps unperturbed, but who, nonetheless, have to find a way to make their living. In their study of sex workers in Kenya, Elmore-Meegan et al. (2004) observe that "sex workers are frequently stigmatised in ways that predispose them to economically marginal living conditions and that make continued sex work necessary in order to maintain household income." The artist uses a unique caricature style of portraying human forms that is colourful, bold and expressive. He uses bright colours and patterns as major elements of attraction as well as the application of separate flat tones that differentiate each of his forms, a style that ensures the images remain flat rather than rounded. The element of exaggeration is consistent with caricature, but he adds facial expressions and other symbolist embellishments that help create the desired atmosphere. 


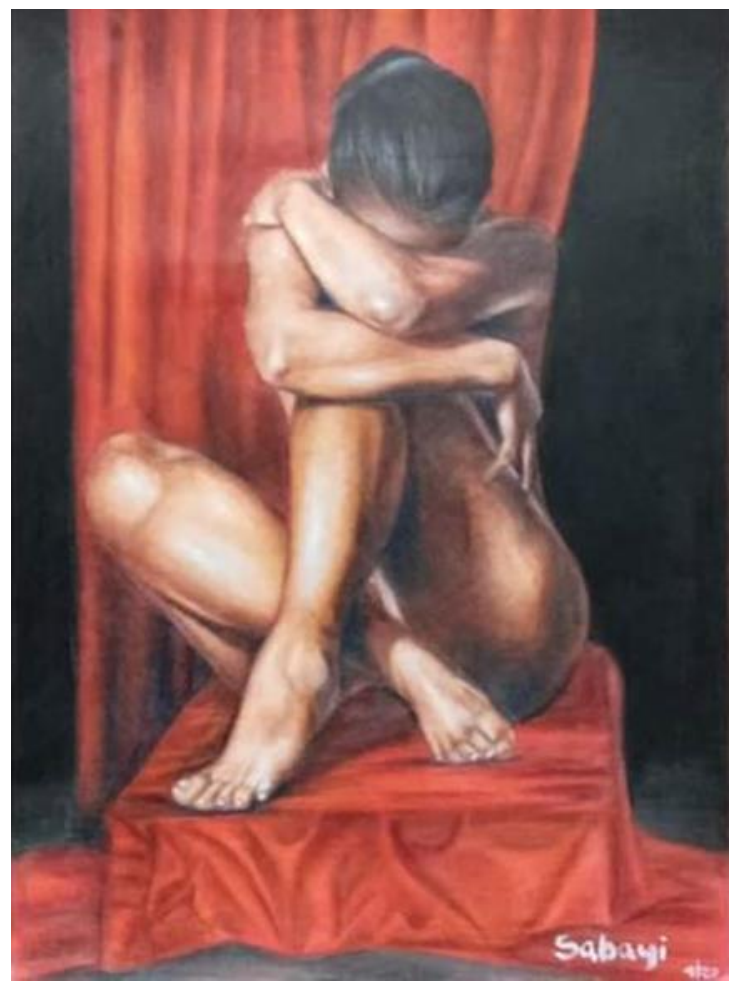

Plate 19. 'A lost soul' (2020)

Artist: Moses Sabayi

Oils on canvas:

Source: Instagram @moses_sabayi

In 'A lost soul' (Plate 19), the artists paints an image of desperation, a depiction of personal upheaval that is painful and lonely and which touches on mental health. This kind of painting is usually an 'expression' that is a response to a known situation that is profound and touching. The forlorn gestural pose of the naked female form and particularly the action of burying her face in her folded arms is not only a physical testimony of her personal upheaval but is symbolic of the fragility of the human mental equilibrium that is often taken for granted. This culminates in the kind of broken mental state that leads to the dark abyss of despair, and hence the title 'A lost soul'. The artist uses the effect of illuminative light, shadows and a very dark background to focus upon the nude female form. This chiaroscuro effect, normally used on wellexecuted realistic forms, has been used by artists across time, notably in the work of Rembrandt, Caravaggio and Goya, to focus attention upon a pertinent part of the painting in order to draw meaning. The female form itself is well modelled with accurate proportions and the use of a variety of tones and shadows upon the body structure in order

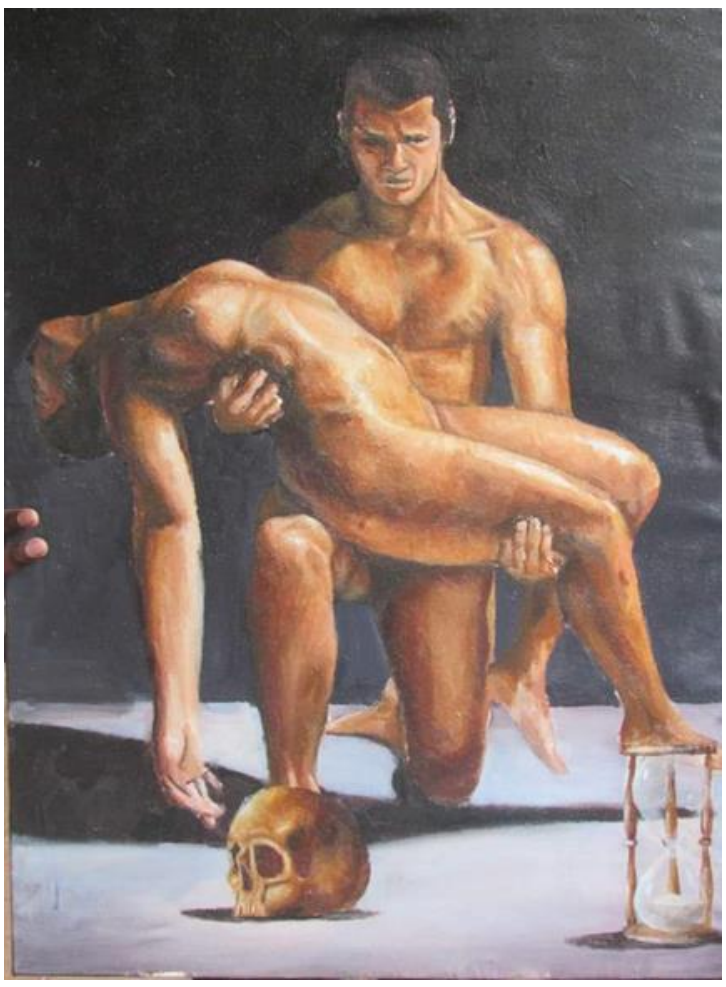

Plate 20. 'Romantic death' (2018)

Artist: Moses Sabayi

Oils on canvas:

Source: Instagram @ moses_sabayi

to bring out the feeling of fullness of body and presence of life.

In 'Romantic death' (Plate 20), the artist depicts an unfolding tragedy of a man carrying the lifeless body of his 'lover' in a moment of great personal despair. The artist again effectively uses the chiaroscuro effect with light falling upon the two human forms from the desired angle, creating shadows in the opposite direction. The rest of the background is composed of light areas and very dark areas creating sharp contrasts that help to enhance the subject matter. The human forms are well-rendered, showing an accurate study of the human body with varying brown tones that depict muscles and other details in both the male and female forms. The human skull in the foreground is symbolic of the manifestation of death. Paintings with such bold images and intensity are often used as 'expressions' of emotions that emanate from personal sorrow, a deep sense of loss or other dramatic experiential episodes. They are less about evoking audience response since, in such

108 | This work is licensed under a Creative Commons Attribution 4.0 International License. 
occurrences, the audience is neither emotional partakers nor 'experiencers' of the tragedy.

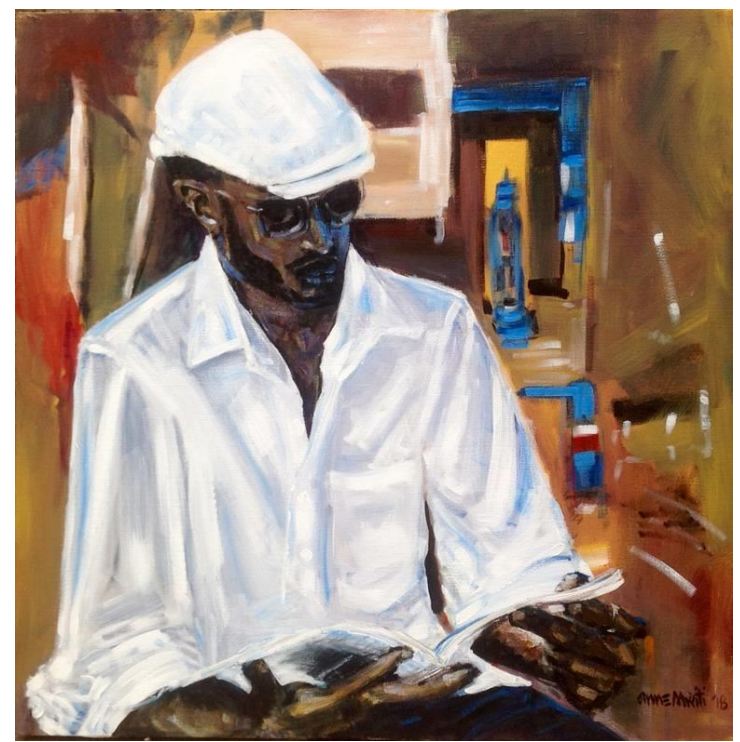

Plate 21. 'Caught in the moment' (2018)

Artist: Anne Mwiti

Acrylics on canvas: 36.3 x $36.3 \mathrm{~cm}$

Source: annemwiti.net

'Caught in the moment' (Plate 21) was inspired by the spontaneity of the pose where the artist sought to capture the moment as the man flipped through the pages of the magazine. The artist was also captivated by the moments of intense concentration on the face of the man as he flipped through the magazine. She, therefore, sought to depict this in the gestural pose and demeanour of the man, as well as the intensity of concentration shown on his face. There are only minimal facial details as compared to a regular face portrait and perhaps due to the angle and distance of study. The facial character, including the sunglasses, is, however, very well defined, suggesting a likeness that is relatable to the identity of the person. The artist uses the effect of illumination to reflect a little blue background colour upon the left side of the face and parts of the shirt. The style itself shows the use of bold brushstrokes and flashes of bright background colours. The use of dark tones contrasts sharply with the white shirt and cap making the individual's image stand out as the centre of interest. These kinds of half-body portraiture are not often

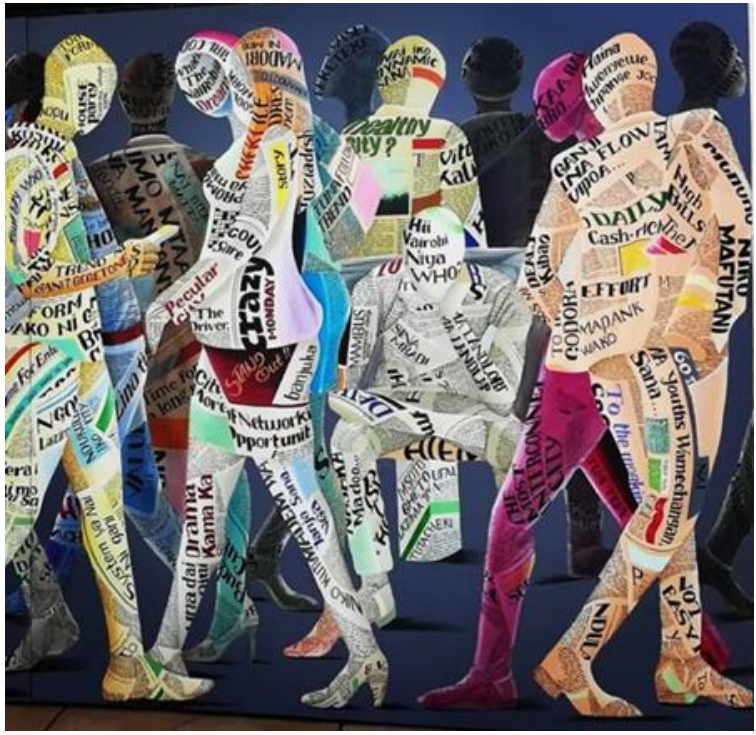

Plate 22. 'The daily stories'

Artist: Nedia Were

Mixed media: $200 \mathrm{~cm}$ x $400 \mathrm{~cm}$

Source:Instagram @artist_nedia_were

concerned with the detailed facial likeness of the subject of study but are more often used to capture the essence or peculiarity of the 'moment' including pertinent aspects of the background.

In 'Daily stories' (Plate 22), the artist depicts a transient crowd all adorned with attires that appear in the image of newspapers. Newspapers are symbolic of news and stories. In this regard, people are in essence walking stories; each individual has his or her daily story to tell, a personal narrative that would be narrated if each were to be given the opportunity to do so. When people walk in the streets, though they appear normal and just going about their business, nobody knows their suffering, pain, worries, frustrations, upheavals or even their triumphs and setbacks. Everybody just walks in the street like empty souls, yet their untold stories are real human stories; they would fill the newspapers just as suggested in the symbolism of the newspaper attires. These untold stories are as varied as the multitude of individuals who make up the transient crowd. 


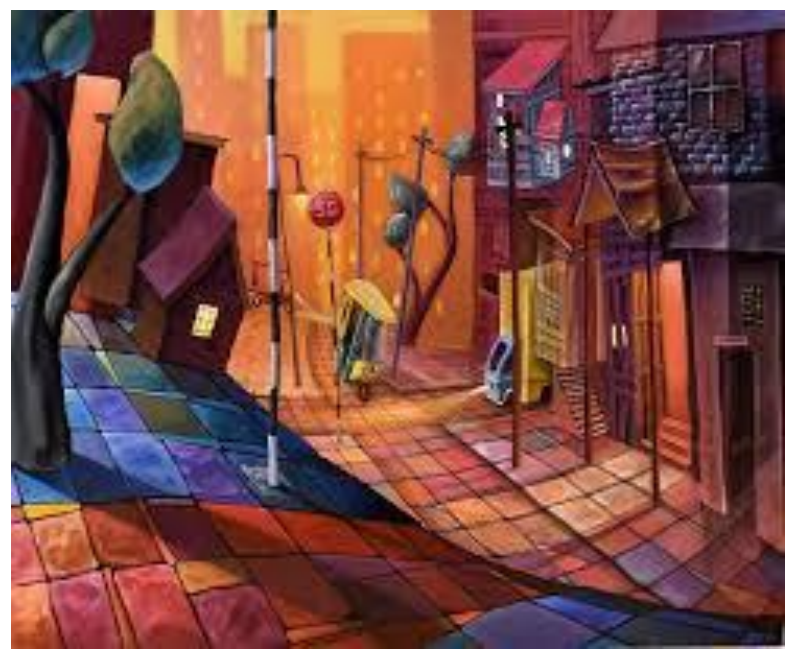

Plate 23. 'Empty street' (2018)

Artist: Michael Musyoka

Acrylics on canvas: $150 \times 199 \mathrm{~cm}$

Source: Instagram@mykemsanii

In 'Empty street' (Plate 23), the surrealistic painting depicts an empty street that also shows a rather bizarre concept of timelessness which is characteristic of surrealism. The looming shadows and bright light falling in some places make it neither dawn nor dusk, just an eerie timelessness upon an empty street in which there is no life. The artist uses a suggestion of false perspective with a lone lighted house on the left side just about to tip over. He applies an array of beautiful tones of colours such as yellows, oranges, purples, blues and arranges them in a manner that creates an intriguing sense of false depth. He also uses the illuminative effect to shine light upon some parts of the painting while also using dark tones on other parts to form contrasts that create an aura of mystery. The static feeling, lack of human life or any visible living thing creates a feeling of eerie silence and gloom. Paintings that depict such unusual or surreal circumstances usually emanate from subconscious imageries that manifest in dreamlike dispensations.

In 'The golden girls' (Plate 24), the artist depicts the 'golden girls' and the audience immediately

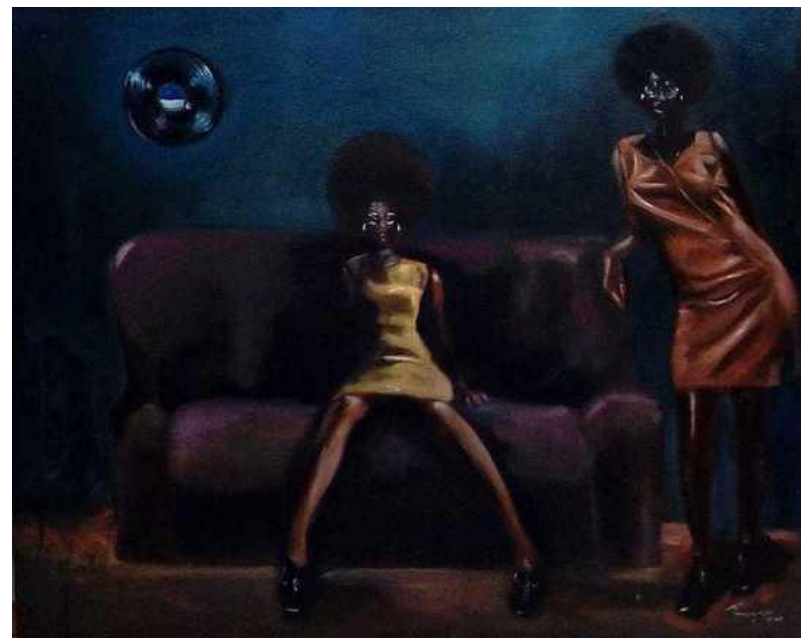

Plate 24. 'The Golden girls'

Artist: Jimmy Kitheka

Oils on canvas: $110 \times 100 \mathrm{~cm}$

Source:Instagram@Jimmy_kitheka

wonders what the golden girls are up to. The engaging painting depicts two girls in rather suggestive gestural poses, sitting and standing in a lounge that suggests the glamour of the nightlife of a bygone era. The artist depicts them wearing high shoes, sunglasses and long Afro-hairstyles of the 1970s. The long play vinyl album on the wall symbolises music, and the blue and purple colours in the painting imply the dimly-lit aura of nightlife. The girls themselves are illuminated to bring out their slender, attractive bodies. The shining light and contrasting shadows also highlight the folds on their dresses and emphasise the intriguing gestural poses. The artist does not suggest they are twilight girls; they may well be just girls having fun in the lounge, going by their youthful, excited demeanour. This is a painting that is reminiscent and, perhaps, nostalgic of a certain bygone era of nightlife as it existed then, and the golden girls are depicted as the 'epitome' of this nightlife as it manifested at the time. Artists are often agents of a societal sense of nostalgia. 


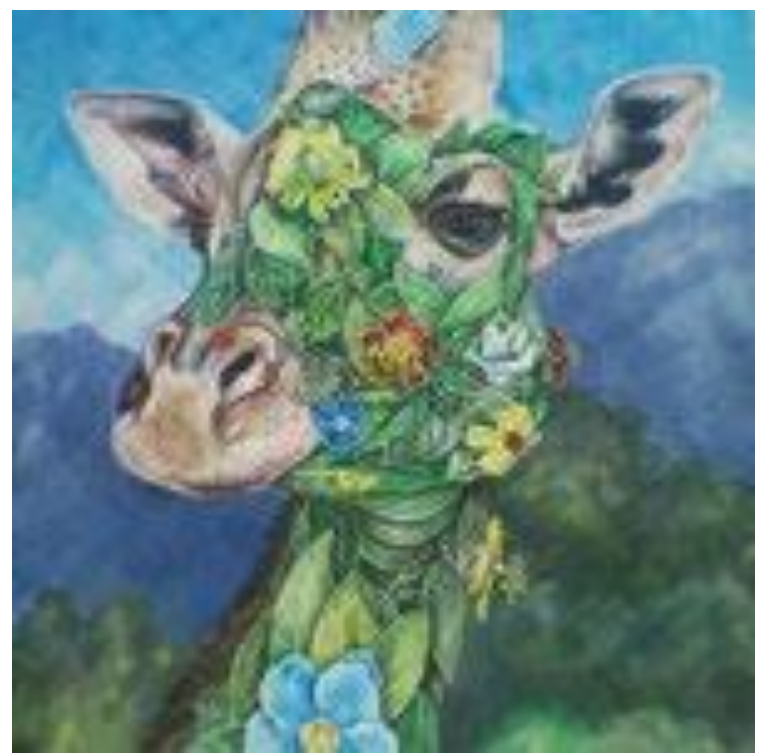

Plate 25. 'untitled.'

Artist: Ron Lukes

Acrylics

Source: image.jimcdn.com

Plate 25 is a nature-inspired painting portraying the intertwining and interdependence of two major aspects of nature; wildlife and the natural environment represented by the blooming of flowers and foliage. This depicts the ingenious use of the images of animals as symbols of the campaign to highlight the need to conserve and sustain nature and the environment on the one hand and the animals themselves on the other. The artist uses the head of a giraffe to carry the message of environmental conservation by painting in leaves and foliage as if they were part of its skin décor. Artist has in recent years used such 'hypothetical paintings' to drive pertinent home messages, particularly in regard to aspects of wildlife and environmental conservation.

'Guest room' (Plate 26) is a simple but very intriguing painting. It depicts the 'goings-on' in the guest room, of which the artist uses suggestive shadows that tell the story of the happenings. This covert approach of portraying subject matter is often very potent since the artist suggests an anticipated or unfolding situation without involving actually painted forms, leaving the audience to draw their own conclusions about the probable outcome. The shadows in this case 'tell' the story of two 'lovers' entering a room, already locked in a romantic embrace, but the artist does not show their actual

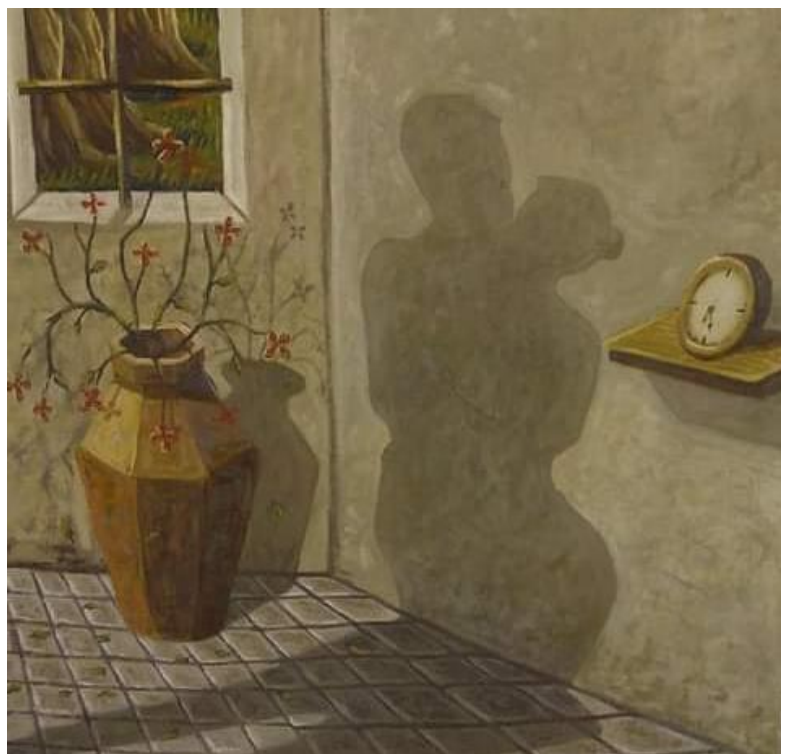

Plate 26. 'Guest room'

Artist: Andrew Otieno

Oils on canvas $-100 \times 120 \mathrm{~cm}$

Source: Facebook - Andrew Otieno

forms, so he cannot be accused of harbouring unsavoury thoughts. Elongated shadows are formed when the sun rays fall behind obstacles, implying that it is probably late in the day when the couple enters the guest room. The painting suggests that the entrance door is ajar or has just been gently pushed open letting in the late evening rays of light that, however, betray the presence of the perceived loving couple. The gestural pose displayed on the shadows suggests a couple who cannot even wait to enter into the privacy of the guest room. The room itself appears sparse and does not suggest anything much; even a bed, which should be its own most obvious symbolic furniture, is lacking. Other than the lone flower vase and the clock on the wall, which indicates the time of day, the artist absolves himself from any responsibility of interpretation and leaves it all to the imagination of the audience. These types of paintings are created to rely on visual clues rather than overt painted forms through which the integral message would otherwise manifest. The role of visual clues or hints is to pass the onus of interpretation directly to the 'mind' of the viewer rather than the artist. Hence, the nature of the viewer's thoughts, whatever direction they may take, can only be attributed to the viewer, not the artist. In this case, the artist does not take responsibility for the viewer's unsavoury thoughts. 


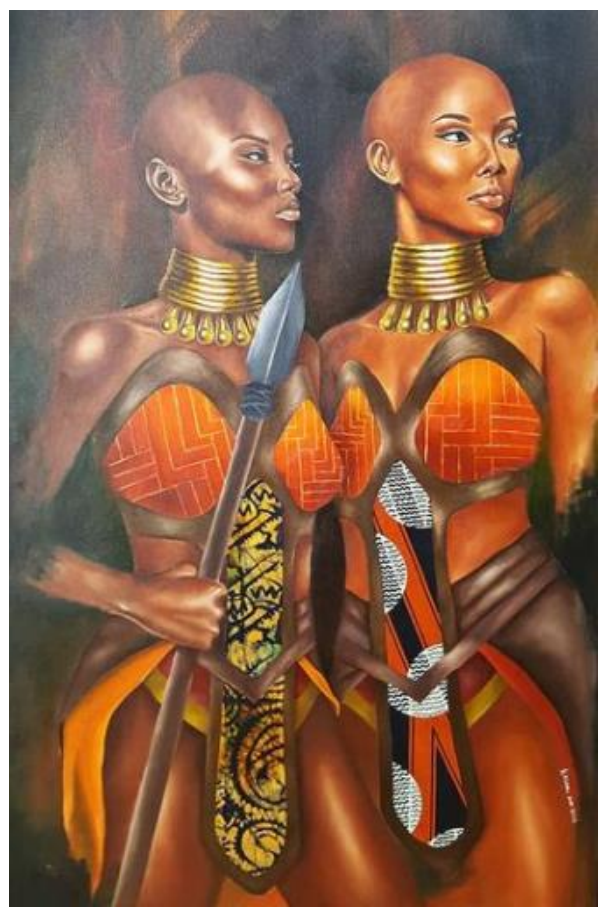

Plate 27. 'Warriors' (2018)

Artist: Kay Katanu

Oils, Acrylics, Kitenge on canvas: 120 x $90 \mathrm{~cm}$

Source:Instagram @Kai_sana

In 'Warriors' (Plate 27), the painting depicts the elegance of two women warriors, placed in the fashionable world of modernity, complete with jewellery and other adornments. The idea of African women warriors is not far-fetched. There were traditional African communities that had women warriors in the real sense of the word, and there were some few African Kingdoms that were led by glamorous and extremely powerful warrior Queens at some point in their history. Some of the most celebrated were the Amazon female military regiment of the Kingdom of Dahomey; Queen Amanirenas of the Kingdom of Kush in present-day Sudan; Queen Amina of the Zazzau Kingdom of Nigeria and Nzinga Mbandi of the Ndongo and Matamba Kingdoms of Angola, among others. The painting, well-executed with intricate details of regalia, seems in its rendition as a romanticisation of the term 'warrior' in order to celebrate the role

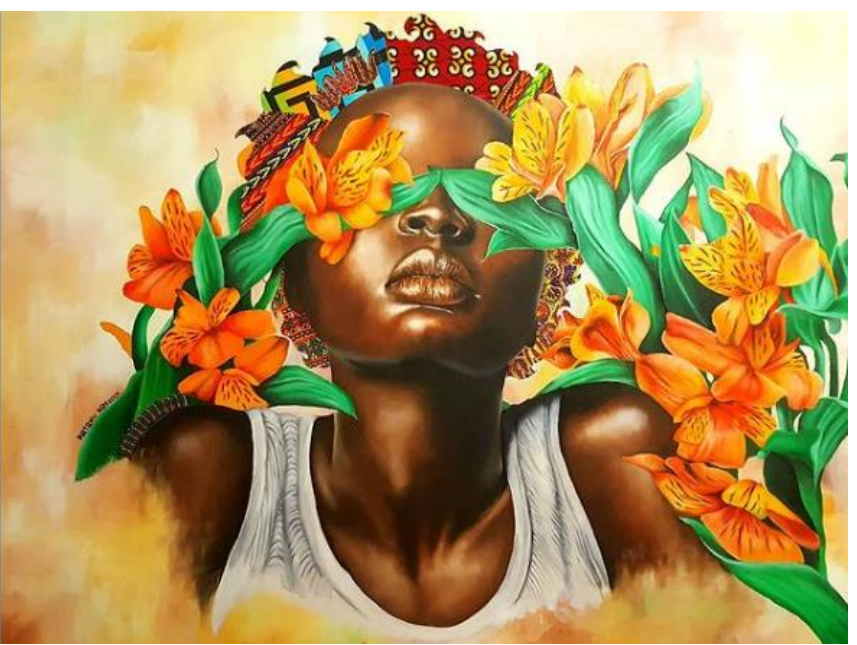

Plate 28. 'Innocent vision'(2017)

Artist: Kay Katanu

Oils, Acrylics, Kitenge on canvas: 90 x $190 \mathrm{~cm}$

Source:Instagram@Kai_sana and potential of women in modern society and, perhaps, what would be if they were to be accorded equal opportunities. The artist is indeed inspired by women empowerment.

In 'Innocent vision' (Plate 28), the painting depicts the face of a youth, blind folded with beautiful flowers and marked with other adornments. This denotes the innocence of youth and that what they see is akin to the purity of vision that is symbolised here by the beauty and freshness of flowers that have not been contaminated. Youth, then, are like little angels; but this innocent vision is ultimately short-lived as they start to be exposed to the myriad of life's complexities that underscore human behavioural culture, beliefs and tendencies. The artist brings out the youthfulness by an accurate study of the youth's facial structure as well as smooth, unblemished skin. 


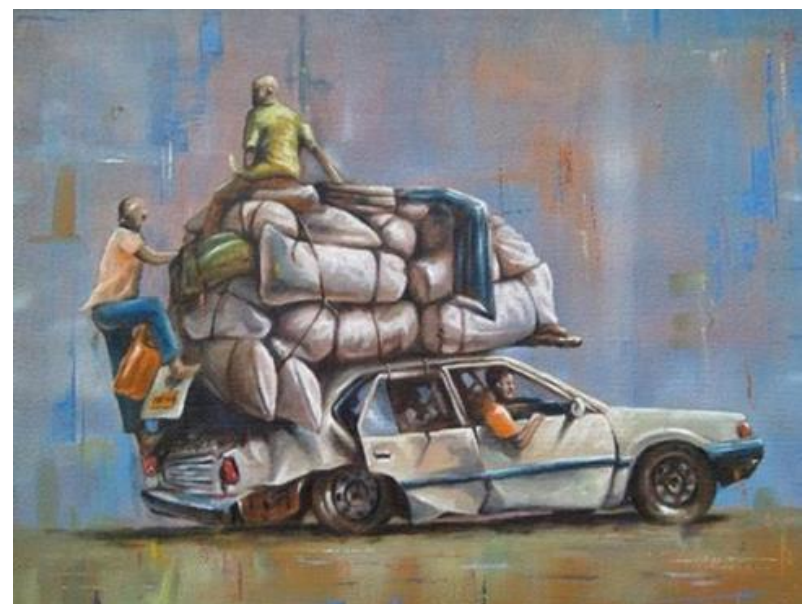

Plate 29. 'Gone are the days'

Artist: Zephania Lukamba

Oils on canvas: $45 \mathrm{~cm}$ x $35 \mathrm{~cm}$

Source: Instagram @zephlukamba

Some paintings depict what is often referred to as the dilemma of life. Often the actions of human beings render the outcome of their work futile and their actions may, at times, appear irrational and counter-productive. Plate 29 depicts this dilemma, which dictates that on the one hand, goods need to be transported in bulk because it makes economic sense to do so; but on the other hand, the goods cannot reach their destination because the vehicle is too overloaded and ill-maintained to make the journey. This culminates in a futile outcome. The irrational part of it is that the people transporting the goods somehow do not comprehend the correlation between the weight of the goods and the mobility of the vehicle. They cannot grasp, or choose to ignore the glaring natural logic that overloading a battered ramshackle of a vehicle to the extent that it cannot move, is not only futile but borders on stupidity. The artist is dumbfounded by this tendency and depicts this in a realistic style that combines an aspect of caricature. While such paintings may appear bizarre or even surreal in a normal worldly sense where order exists, when they are placed in the context of their occurrence, then it becomes somewhat

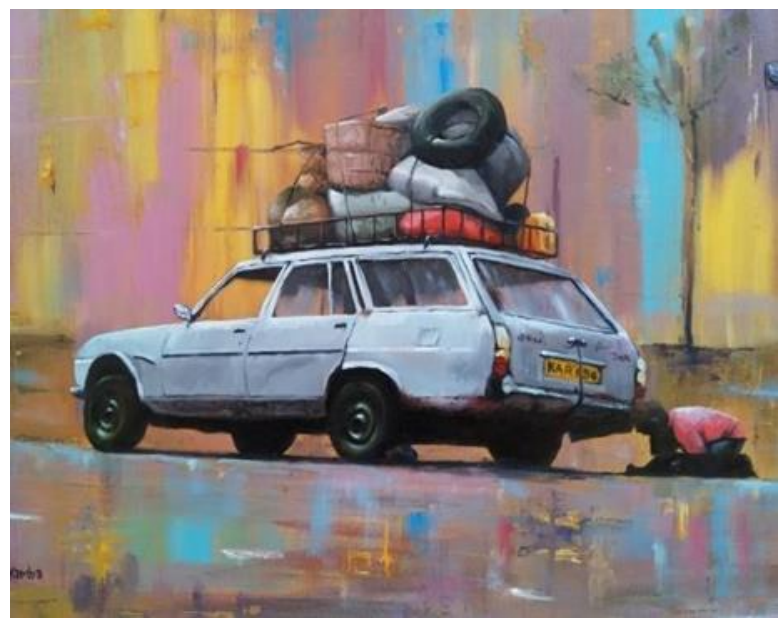

Plate 30. 'What is this again?' (2020)

Artist: Zephania Lukamba

Oils on canvas:

Source: Instagram @zephlukamba

comprehensible why people make such seemingly irrational decisions. Others may argue that this has nothing to do with business considerations or mitigation against the ravages of poverty, but it is simply a misplaced mindset and a character flaw that culminates in such self-defeating recklessness.

While the depiction of such futile audacity (Plate 29 ) is annoying, Nini hii tena?- what is this again? (Plate 30) is amusing. The driver of the overloaded vehicle is also incapable of comprehending the irony of his own ineptitude. He cannot fathom why the vehicle should have endless problems even though it is obvious that his tendency to overload the vehicle is the major cause. These kinds of paintings are often used to shed light upon more pertinent human phenomena beyond the immediate visual subject matter. Both paintings show that human beings are capable of operating completely incongruous with the realm of natural logic and that it is impossible to guarantee that people shall always act rationally or within the tenets of common sense, even though their actions are ironic to their individual and collective detriment. 


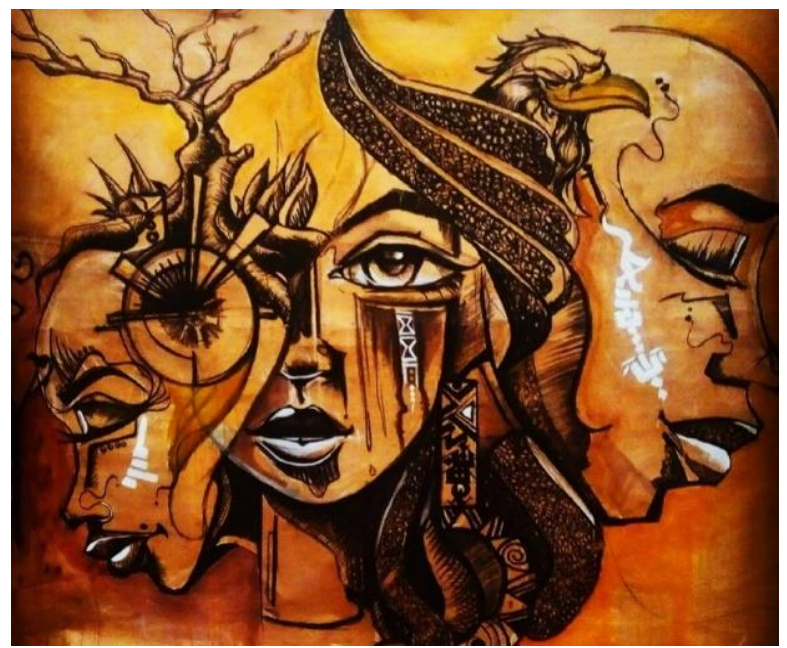

Plate 31. 'Sivana' (2017)

Artist: Chelagat Cherwon

Acrylics and charcoal:

Source: behance.net/NANEY_CHEIACHELWEK

In 'Sivana' (Plate 31), the artist depicts three faces of a young girl. Inspired by a sad dream, the artist narrates the beautiful story of the little girl 'Sivana' who appears in the dream and beckons the artist to follow her into a new dispensation of great light and enlightenment. Coincidently, the name 'Sivana' means "an oasis of enlightenment; a place of peace, love, joy and hope in a chaotic world." (Artist) According to the Artist, the three faces show the delicate balance of mind, body and soul; ideally, the triad should be functional and harmonious. When there is a disconnect in this harmonious triad, the soul is sad and forlorn, which is what is depicted by the face in the centre. The face with the sprouting tree represents the body and the continuity of life, which is symbolised by the presence of roots. As long as the tree has roots, though it may currently bear leaves, new leaves shall ultimately sprout and the tree shall blossom with new life, which is symbolic of infinite hope. The face with the eagle symbolises the profoundness of the state of mind; like the eagle's mind, "if we keep our minds focused and undeterred, we can ultimately achieve our goals and dreams" (Artist). These kinds of paintings are testimony to how subject matter can be derived from dreamlike imageries. These sporadic imageries are not themselves thematic; they just manifest. But when the artist is able to transform the imageries

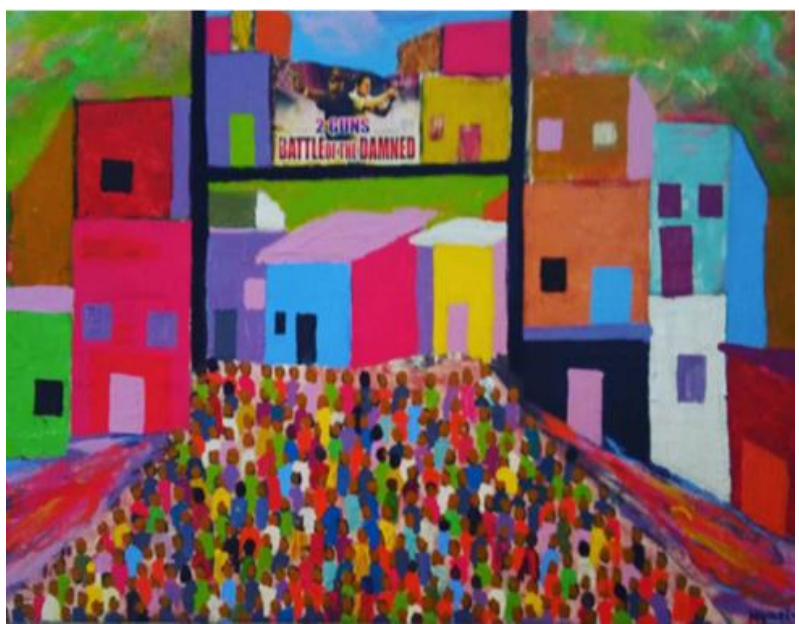

Plate 32. 'Movie star' artist: Charles Ngatia

Acrylics on canvas: $70 \mathrm{~cm}$ x $80 \mathrm{~cm}$

Source: Instagram @ charlesmgatiamwendw

into actual visual artwork that can be shared with the audience, then a theme can be attached to the work. It can be presumed, therefore, that dreamlike imageries may bear covert themes that are not fathomable until there is some form of conscious interpretation.

In 'Movie star' (Plate 32), the painting depicts a large crowd gathered to watch an outdoor movie in the densely populated 'Eastlands. The sprawling residential area is symbolised by brightly coloured, closely-knit buildings executed in straight lines and geometric shapes, a characteristic of the artist's style. The artist adopts bright colours to replace the dull natural colours of endless buildings that dot the landscape. The bright colours on the buildings and on the crowd are symbolic of the need for warmth and hope in an atmosphere of congestion, struggle and despair. The movie star narrative is consistent with the kind of dreamlike, utopian mode that people in such environments often adopt; of an imagined highlife, seen through the life of the movie star. This mode that plays out like a trance within the duration of the movie temporarily substitutes for their real-life reference; everyone relishes the imageries of being a movie star, lost in their own utopian world that exists only in their bizarre imagination. 


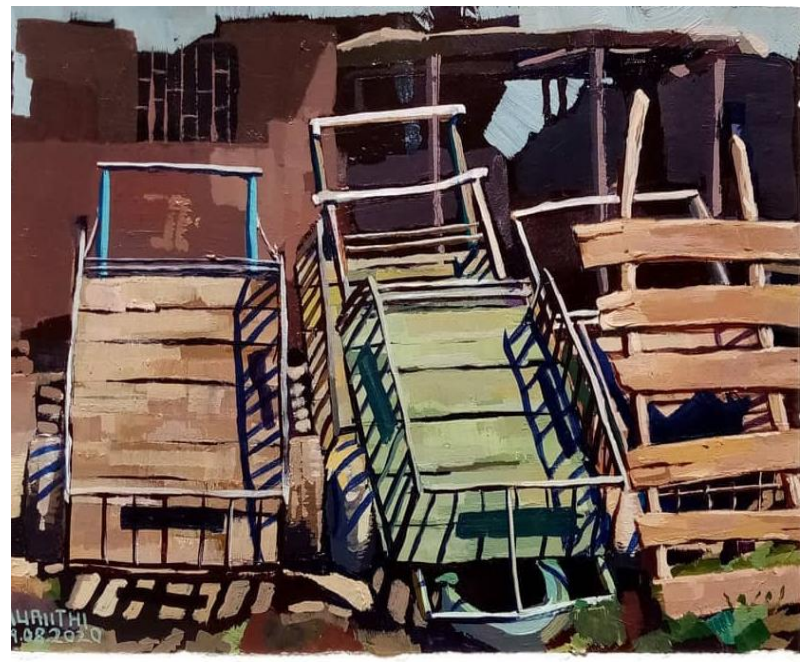

Plate 33. 'Mikokoo'

Artist: Samuel Mureithi

Acrylics on paper: $39 \times 28 \mathrm{~cm}$

Source: Instagram @mureithi contemporary

In 'Mikokoo' (Plate 33), the artist depicts unused handcarts. Handcarts are a symbol of daily struggle in certain parts of the city, particularly those that host small scale traders. They are used as cheap human labour transport that assists small scale traders to ferry their goods around and are an important street component of the economic activities of the catchment areas in which they exist. The artist shows them parked in a desolate environment which suggests a lack of business and a symbolic emptiness that is sad to see. The artist uses the effect of falling light and varied tones, sharp contrasts as well as shadows to create a sunny mid-day effect, the time of day that the handcart pushers should be at the height of their errands. This is a painting that highlights the plight of ordinary struggling people, the kind of whom the greater society tends to ignore in an increasingly uncaring and incompassionate world. 'Mikokoo' is a street word for 'mikokoteni' which means handcarts.

Young angel (Plate 34) depicts a young African child wearing colourful clothes with beautiful tones and folds that underscore the playful gestural pose. Paintings of children have the ability to suggest childlike innocence, a visual attribute that is more believable when seen in the context of a child's accurately portrayed facial features than is possible in paintings that feature adult faces. The painting accurately shows the image of the child's pertinent features such as the wide eyes, small nose, little lips

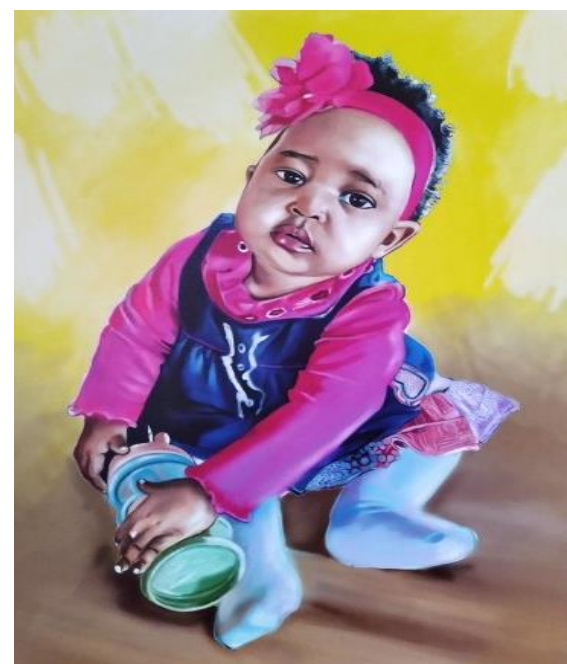

Plate 34. 'Young angel'

Artist: Eric Wambugu

Digital painting: $59.4 \mathrm{~cm}$ x $29.7 \mathrm{~cm}$

Source: Artist

and rounded cheeks all done with smooth modelled tones, which contribute to the feeling of innocence. The twist of the little body is realistic and charming. This child fits into the description of an 'a icon of innocence', portraying an angelic disposition associated with children of this age. It can be noted, though, that as children grow older, this aura of infinite innocence ultimately ebbs away as a result of the transient nature of childhood and its inevitable vulnerabilities.

\section{Observations and General Overview}

\section{Thematic Approach as a Basis for the Creation of Paintings}

It can be observed that there is certainly a robust thematic approach to many of the paintings featured in this paper and that there is evidence of reference to varied themes that focus on issues that are prevalent or pertinent to the lives of people within their environment. The influence of themes, therefore, as an integral source of formative ideas for creating artwork cannot be underestimated. The element of social connectivity and general enlightenment that is greatly aided by a wider or expanded media space tends to highlight some of these occurrences and related events. This, in turn, creates the motivation and need for artists to create paintings in their quest to respond to and address these issues from a visual perspective. When artists 
in such circumstances respond to thematic undercurrents, they tend to naturally adopt a 'visual commentary' approach, instilling in their paintings a unique aura of expressiveness. This expressiveness is what resonates back and forth with the audience who may respond to the content of the paintings in a given way, be it with empathy, concurrence, reservation, scepticism, consternation or even rejection. Whichever way the responses manifest themselves, the audience is, hence, able to decode the meanings therein. This becomes even more profound when the paintings are subjected to interpretation where they attract a great deal of 'interpretive dialogue' (Barette, 1994) as well as focused debate.

\section{Derivation of Subject Matter}

A theme is broad and serves as an anchorage for ideas. The mere mention of a theme is enough to set the artist's mind rolling with countless imageries of related possibilities. As has been observed earlier, this then creates the opportunity for the derivation of specific subject matter that the artist wishes to tackle. This is a spontaneous creative process usually done through a series of sketches. On the subject matter itself, this paper views it from the perspective of purpose and intent. Every painting that is created by an artist is 'about' something; there is no painting that entirely lacks a creative, aesthetic or expressive purpose. In meeting this purpose, an artist must, therefore, come up with a compressed idea that can be converted into a viable piece of artwork that is then subjected to the usual compositional or formal process and fitted in within the picture plane. All the paintings in this paper show spontaneity of emergent subject matter and in many instances, it is not difficult to decipher what the artists 'purposed' to bring forth. The subject matter, in this context, is intertwined with the usage of elements and principles of art that constitute the formal arrangement in a given work. The subject matter is usually, but not always, suggested in the title of the work, but where it is suggested, the title helps to enhance the substance of the painting itself in a verbal way. In Plate 13 , it would be difficult to miss the boisterous demeanour of the market women as they go about their business; the artist uses the two figures in the foreground to bring out the subject matter and then adds all relevant background details including two other half forms to wrap up the composition. The composition as a whole includes other observational details and suggestive hints which constitute the overall 'content' of the painting. The observational details may entail, in this case, the bright colours of the womens' attire, their physical body features and their surroundings, including their wares. Suggestive hints entail certain attributes that may not be expressed visually but are implied through rhythmical gestural poses or facial expressions. The audience is able to determine that the women bear a degree of restlessness, joyfulness, resilience and perhaps even a tendency towards incessant gossip.

\section{Use of Colour}

The use of colour as a key element of art continues to dominate the way paintings are rendered. It is evident that the artists featured in this paper are aware of the influence of colour as an aesthetic tool as well as its ability to enhance and propagate the meaning contained in their paintings. In 'Movie Star' (Plate 32), the artist adopts bright colours as a substitute to the otherwise dull colours of the sprawling buildings that exist in reality and extends the same to the crowd. These bright colours on the buildings and on the crowd not only add to the aesthetical value of the painting itself but are symbolic of its meaning; that of the need to inject a modicum of warmth and hope in the lives of the residents who exist in an atmosphere of congestion, struggle and despair.

\section{Stylistic Approach}

The artists vary in their stylistic approach to their work and the paintings featured show varied influences in terms of style. These styles range from the influence of hyperrealism, realism itself, surrealism, abstraction, impressionism and expressionism. The artists indicated that they paint in the style that they find most comfortable and which best helps them address themes and articulate their ideas.

\section{Technique}

The artists utilised a variety of techniques in the application of colour in their work. Some used heavy or bold brushstrokes to apply bright colours and suggest textures, while others prefer smooth, fine or rhythmical brushstrokes that created smooth, 
tender effects. Many of the artists also applied the effect of shining light to highlight or draw attention to pertinent aspects of their painting by sharply contrasting the illuminative effect with shadows and dark backgrounds. This was more or less related to their stylistic approach and medium of choice. It is observable that technique is a factor that helps to give an artist his or her artistic identity.

\section{Expression of Work}

In the context of this paper, expression is defined as the kind of visual rendition that is emanative from an artist's emotions and feelings where he or she paints as an outlet for these emotions and feelings. Subsequently, some of the paintings can be categorised as bearing expression. In 'Sivana' (Plate 31), the artist expresses her emotions through the symbolism of the three faces, whose visual formulation is derived specifically from a dream. The artist describes the dream as having been triggered and possibly related to other personal upheavals intimated but not necessarily revealed. This painting is, therefore, an expression of a personal odyssey and the quest to find personal revival. In Romantic death (Plate 20), the intense sense of tragedy seems genuinely experiential and, therefore, deeply felt and is expressed accordingly. It is not clear, however, whether the artist is the 'experiencer' of the actual tragedy, but still, the emotion is expressed in a deeply personal way. Robinson (2007) asserts that "Whether something is or is not an expression depends on whether it is a product of a person or agent who is expressing his or her emotions."

\section{Expressiveness of Work}

If expressiveness in a painting is defined as the ability for a painting to elicit emotional or other responses from the audience as a reaction or response to the painting, then some of the paintings can be categorised as bearing expressiveness. In $A$ lost soul (Plate 19), the painting is an expression of the emotions of this tormented individual. Though the person featured in the painting is not the artist himself, such paintings are often used as 'conduits of expression' of individual emotions, which implies that although the artist himself is not the 'experiencer' of the torment, he becomes the conduit through which the emotions are expressed.
He is not within the lost soul but is, however, in a position to perceive the predicament of the experiencer through direct interaction with or observing her ordeal. In clarifying the role of expressiveness in a painting, Robinson (2007) observes, "But expressions are not just outpourings by expressers of emotion; they are also means of communicating emotions to others. In ordinary life, interpersonal communication via the expression of emotion is essential to the smooth functioning of human social life." In the intriguing 'Guest room' (Plate 22), the artist leaves the interpretation entirely upon the imagination of the audience by applying the artistic strategy of using the 'implied action' in the painted shadows as a visual hint.

In 'Daily stories' (Plate 26), the artist engages the audience by the portrayal of the transient crowd as being both the carriers of news and stories as well as being walking 'untold' stories themselves. The audience can, therefore, easily substitute the transient crowd with themselves and realise that their stories, though potent and real, are really never told. In Plate 29, the artist paints a very expressive painting, combining elements of realism and caricature to depict the perplexing ineptitude of human nature. In the provocative painting of women, 'I love Nairobi 38' (Plate 18), the artist leaves the unempathetic minds of the audience seeking answers about the implication of the images of these women.

\section{Ease of Interpretation}

It can be observed that the paintings featured in this paper are generally straightforward in their ability to depict the meaning and that artists did not seem to favour paintings that harbour hidden meanings or attracted multiple interpretations. However, this paper contends that multiple interpretations often manifest themselves spontaneously, even in instances where the artist does not intend them to occur. This is because the audience in these instances 'see' what strikes their imagination and not necessarily what the artist intended. In 'The Golden Girls' (Plate 24), the painting is not necessarily explicit; it suggests but does not tell a clear narrative; the audience is left wondering what the mission of the golden girls really is; where are they? Why are they there? and indeed, who are they? This opens the ground for a number of 
interpretations about which the artist may not have anything much to say. In 'Empty Street' (Plate 23), the probability of multiple interpretations is made much more apparent because of the surrealistic nature of the painting itself

\section{Contextual Anchorage}

It was observed in the paintings that contextual anchorage is perhaps more profound in the interpretation of themes and derivation of subject matter than it is generally thought. In their interviews, artists indicated that in dealing with the subject matter and the formulation of ideas including the juxtaposition of concepts, they are almost always guided by the appropriate contextualisation of their work; they include certain visual clues or hints in their work, they refer to certain known referents, they feature certain situations, follow certain historical and cultural dictates, depict certain peculiarities, create targeted aesthetical appeal and even use certain colours to emphasise certain phenomena. Subsequently, they elicit certain responses and emotions from the audience who are more or less familiar with these contexts. They contend that without contextualisation, their work would lose a significant tenet that anchors the integral meaning and the individual paintings would, therefore, not make sense to the audience. When the viewers do not readily comprehend meaning in a work of art, particularly in a painting, they create their own meaning anyway, therefore carrying away with them a completely different idea. This should not be mistaken with the notion of multiple interpretations; a completely misplaced interpretation is in such circumstances, counter-productive.

\section{A Generally Enlightened Audience (as a result of social media and other media outlets that has been of great influence in recent years)}

The kind of subject matter that is evident in these paintings shows that artists are confident that their audiences are well placed to interpret the work because they can associate with the content and can understand its context. This is attributed to a significant extent to an expanded media space, the rise of media outlets, particularly social media, where news and information about events and occurrences in many segments of society are readily circulated and available to people. The resultant exposure implies that audiences are most likely going to be better placed to resonate with the subject matter and content that the artists express in their paintings. In the same token, artists use social media outlets as channels for marketing and selling their work.

\section{CONCLUSION}

\section{Multiple Interpretations}

Although it is acknowledged that artworks may bear multiple interpretations, this paper contends that in the interpretations of paintings, the artists intent remains pivotal in the unravelling of the intended message. The study concludes that in many instances, artists do not purposely intend their work to bear multiple interpretations since the formulation of their ideas is clear-cut and forthright in their minds from the onset. This should not be mistaken for dogmatism, but rather from the point of view that what they want to 'express' is often clearly defined in their minds. In this regard, some artists become perplexed that their work seems to bear interpretations other than the ones they intended. This then culminates in the suggestion of new meaning that they are not privy to or over which they seem to be bear no control.

The issue of multiple interpretations subsequently remains controversial since there are other schools of thought who maintain that the artist's intent is important but not critical in interpretational outcomes and that artists, through their work, act as triggering agents, not 'idealistic gurus', towards artistic discourse, arguments, perspectives, persuasions, and ultimately interpretational possibilities. This school of thought then contends that the artist's initial intent, therefore, becomes only one of these interpretational possibilities. An example of the potency of multi-interpretations in paintings is Blue to Blue (Plate 10). While the artists were content to study the qualities of the jean material fabric as a garment or drapery, his painting elicited a completely different interpretation from one viewer who saw it as a visual depiction of the philosophical notion of an 'empty soul' which, by extension, cannot be present in a non-existent body. 
Another viewer interpreted it as 'emptiness of character'. In this case, therefore, the artist's simple intention is known, yet the two viewers derive their own more complex interpretations that are apparently thoughtful, coherent and persuasive. Subsequently, as noted earlier in the outlined guidelines of interpretation (Barrett, 1994), these interpretations do not have to match the artist's intent for the work since the objects of interpretation is the artworks, not the artist. Further, the varied interpretations of the same painting provide different perspectives or points of view that suggest or culminate in a 'new meaning' which appears viable but which the artist did not necessarily intend.

\section{Role of Artists}

When artwork is subjected to interpretation and meaning is drawn, it becomes clear that artists contribute a great deal to the quality of social discourse on matters that affect society. Through their paintings, they help to highlight pertinent issues, occurrences and events that spur appropriate interventions and solutions. This is mainly done through the expressiveness of their work and quite often through the 'expression' of their own individual feelings and emotions. The whole sum total of their work, including their thematic foundation, derivation of subject matter, rationalisation of ideas, formulation of content and contextualisation of their work, all attract the kind of responses from the audience that result in concrete responsive action and activism as well as influencing policy.

\section{Thematic Concept is Still Viable and Useful}

A thematic approach towards the creation of an artwork is still a viable basis for the galvanisation of artistic ideas. Themes define all aspects of human endeavour and are, therefore, a repository of ideas that artist continuously exploit.

\section{Subject Matter and Content are Intertwined and Important in the Construction of Meaning in a Work of Art}

The derivation of subject matter from themes is still a pertinent way in which artists create their work and formulate their content. It is a worthy pathway towards the rationalisation of ideas and thoughtfulness, the reductionism of complex human phenomena, examination and analysis of transient events and occurrences that are pertinent to the wellbeing of communities and society. The derivation of subject matter, therefore, ultimately helps in the description of life's complexities, human behavioural tendencies and the focus on many other phenomena. This subsequently helps in the crystallisation of 'content' in works of art that ultimately gives them their meaning and helps society to better understand itself and constantly seek solutions to both recurrent and emergent issues.

\section{Context is just as Important as Content}

When the content of a painting is examined, the audience comprehends the meaning or message portrayed according to the context in which the artist portrays that message. This is important because artists work within the environment in which they live, operate and observe. Since the audience also lives in the same environment, then there occurs a mutual platform upon which artistic interaction, discourse and understanding converge. In instances where the painting is not well contextualised, the message itself can be misconstrued and the content may seem to lack the necessary resonance to make visual sense. This is different from multiple interpretations of a painting; multiple interpretations occur when there exists resonance with the content of the painting, only that the audience perceives that content from different perspectives which are deemed plausible.

\section{An Enlightened Audience and Expanded Media Helps in the Comprehension of Artistic Ideas}

Expanded media space enables the audience to be significantly more aware of occurrences in their environment and become more enlightened about issues affecting them. This indicates that they are most likely to come across circulating news and information, particularly through social media and other outlets, that generally increase their awareness of what transpires around them. This means that they develop a significant ability to interpret artwork in the context in which it is created and are able to decipher meaning much better than would otherwise be the case. 


\section{Work Seems to be much more audience Oriented than Self-Centred}

It can be concluded that the paintings featured in this paper bear the kind of expressiveness that appeals to the audience. Subsequently, the artists seem more inclined towards engaging their audience and eliciting their responses about the pertinent social issues rather than paintings that are inclined towards the expression of personal emotions or feelings. This paper does not, however, suggest that this was in any way premeditated, methodical or should indeed always be the case; it could well have been just coincidental that the paintings happened to bear expressiveness that tended to be audience inclined. Artists retain the freedom to always express whatever they feel appropriate and necessary

\section{REFERENCES}

Barenscott, D. (2016). Focus on Fundamentals of Visual Art \& Culture: Context. Dorothybarenscott.com. Retrieved on March 16, 2021; http://www.dorothybarenscott.com/http/ wwwdorothybarenscottcom/2016/1/23/focuson-fundamentals-of-visual-art-culture-context

Barrett, T. (1994). Principles for interpreting art.Art Education,47(5), 813. Doi:https://doi.org/10.23 $07 / 3193496$

Belton, R. J. (1996). Art history: A preliminary Handbook? Retrieved on March 16, 2021; https://d1wqtxts1xzle7.cloudfront.net/43880410 /Preliminary_Handbook.pdf?1458371315

Berends, B. (2018). Why a theme is no important for an artist. Biancaberends.com. Retrieved on March 5, 2021; https://www.biancaberends.com /blog/blog_posts/why-a-theme-when-creating

Carrubba, J. (2016). Style, Subject Matter, Content and Context in Art. Joannecarrubba.wordpress.c om. Retrieved on March 4, 2021; https://joannecarrubba.wordpress.com/2016/05/ $12 /$ style-subject-matter-content-and-context-inart/

Elmore-Meegan, M., Conroy, R. M., \& Agala, C. B. (2004). Sex workers in Kenya, numbers of clients and associated risks: an exploratory survey. Reproductive health matters, 12(23), 50-
57. Doi: doi/full/10.1016/S09688080\%2804\%2 923125-1

Gale, A. (2018). How to analyse an artwork: s stepby-step guide. Studentartguide.com. Retrieved on March 14, 2021; https://www.studentartguid e.com/articles/how-to-analyze-an-artwork

Glatstein, J. (2009). ARTSEDGE: Formal Visual Analysis: The Elements and Principles of Composition. ARTSEDGE: The Kennedy Center. Retrieved on March 3, 2021; http://artsedge.kennedycenter.org/content/3902/

Livneva, A. (2018). Art Themes At Virtodu Art Gallery. Virtsosuart.com. Retrieved on February 21, 2021; https://www.virtosuart.com/blog/artthemes-at-virtosu-art-gallery\#:

Ocvirk, O. G., Stinson, R. E., Wigg, P. R., Bone, R. O., \& Cayton, D. L. (2013). Art fundamentals: Theory and practice. Twelfth Edition. Personal.utdallas.edu. Retrieved on March 4, 2021; https://personal.utdallas.edu/ mel024000 /pages/2D_Design/Components_of_Art/Compo nents_of_Art.html

Robinson, J. (2007). Expression and Expressiveness in Art. Postgraduate Journal of Aesthetics, 4(2). Retrieved on March 19, 2021, https://core.ac.uk/download/pdf/226757022.pdf

$120 \mid$ This work is licensed under a Creative Commons Attribution 4.0 International License. 